Keywords: Column

experiments, PSD, Zeta

potential, XRD, SEM,

contaminant transport

Retention: Permanent

\title{
Mobilization and Characterization of Colloids Generated from Cement Leachates Moving Through a SRS Sandy Sediment
}

Dien $\mathrm{Li}^{1}{ }^{1}$, Kimberly A. Roberts ${ }^{1}$,

Daniel I. Kaplan ${ }^{1}$, and John C. Seaman ${ }^{2}$

1 SRNL

2 Savannah River Ecology Laboratory, University of Georgia, Aiken, SC 29808

September 20, 2011

Savannah River National Laboratory

Savannah River Nuclear Solutions, LLC Aiken, SC 29808

Prepared for the U.S. Department of Energy

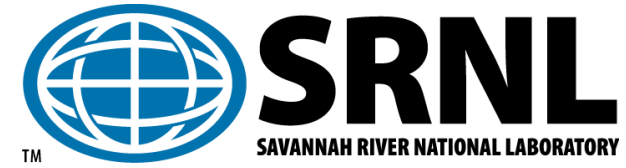
under contract number DE-AC09-

08SR22470. 
SRNL-STI-2011-00498

Rev. 0

\section{DISCLAIMER}

This work was prepared under an agreement with and funded by the U.S. Government. Neither the U.S. Government or its employees, nor any of its contractors, subcontractors or their employees, makes any express or implied:

1. Warranty or assumes any legal liability for the accuracy, completeness, or for the use or results of such use of any information, product, or process disclosed; or

2. Representation that such use or results of such use would not infringe privately owned rights; or

3. Endorsement or recommendation of any specifically identified commercial product, process, or service.

Any views and opinions of authors expressed in this work do not necessarily state or reflect those of the United States Government, or its contractors, or subcontractors.

\section{Printed in the United States of America}

Prepared for U.S. Department of Energy 
SRNL-STI-2011-00498

Rev. 0

\section{REVIEWS AND APPROVALS}

Dien Li, Co-author, Environment Science and Biotechnology

Date

Kimberly A. Roberts, Co-author, Radiological Performance Assessment

Date

Daniel I. Kaplan, Co-author, Environment Science and Biotechnology

Date

John C. Seaman, Co-author, Savannah River Ecology Laboratory

Date

Philip M. Almond, Technical Reviewer, Engineering Process Development

Date

David A. Crowley, Manager, Radiological Performance Assessment

Date

John J. Mayer, Manager, Environment Analysis

Date

Bob S. Aylward, Manager, Environment Restoration Technology

Date 


\section{EXECUTIVE SUMMARY}

Naturally occurring mobile colloids are ubiquitous and are involved in many important processes in the subsurface zone. For example, colloid generation and subsequent mobilization represent a possible mechanism for the transport of contaminants including radionuclides in the subsurface environments. For colloid-facilitated transport to be significant, three criteria must be met: (1) colloids must be generated; (2) contaminants must associate with the colloids preferentially to the immobile solid phase (aquifer); and (3) colloids must be transported through the groundwater or in subsurface environments once these colloids start moving they become "mobile colloids". Although some experimental investigations of particle release in natural porous media have been conducted, the detailed mechanisms of release and re-deposition of colloidal particles within natural porous media are poorly understood. Even though this vector of transport is known, the extent of its importance is not known yet. Colloid-facilitated transport of trace radionuclides has been observed in the field, thus demonstrating a possible radiological risk associated with the colloids.

Previous laboratory studies showed that SRS sediments might have the potential to form mobile colloid suspensions over an environmentally credible range of aqueous-phase chemistries, especially at elevated $\mathrm{pH}$ levels. Underground concrete vaults and structures, which generate high $\mathrm{pH}$ leachates, have been widely built for nuclear waste containment at the SRS and throughout the DOE complex. Therefore, it is important to evaluate the impacts of colloid mobilization as a potential vector for facilitated radionuclide transport. The objective of this study was to determine whether cementitious leachates would promote the in situ mobilization of natural colloidal particles from a SRS sandy sediment. The intent was to determine if a cementitious surface or subsurface structure would create plumes that could produce conditions conducive to sediment dispersion and mobile colloid generation, either by 1) mineral precipitation of the cement leachate interacting with SRS groundwater, or 2) the release of colloidal particles from a SRS sandy sediment.

Titration of cement leachate solution with SRS groundwater showed a slight increase of turbidity ( $<5 \mathrm{NTU}$; a proxy for colloid concentration) with increase in $\mathrm{pH}$, suggesting that some in situ precipitation was occurring at the higher $\mathrm{pH}$ values. SEM images of the greater than $1 \mathrm{kDa}(\sim 1 \mathrm{~nm})$ ultrafiltered titrated solutions also showed a very sparse population of material that were very large particulates $(>5 \mu \mathrm{m})$ that would not be mobile through porous media. SEM images indicated that the material collected on the $1 \mathrm{kDa}$ filter was on the order of a micron putting this material in the particulate and not colloidal size range. These results indicated that the cement leachate solution interacting with groundwater alone is unlikely a sufficient source of colloid generation as a vector for transporting contaminants.

Column studies were conducted with cement leachate simulant (CLS) and genuine cement leachate (GCL) in contact with SRS sandy sediment. The cation chemistries of influents and effluents in column studies with SRS sediment were analyzed by ICP-OES, while the mobilized colloids were characterized using XRD, SEM, EDX, PSD and Zeta potential. The mobilization mechanisms of colloids in SRS sandy sediment by cement leachates were briefly discussed. An initial sharp colloid plume front formed, and then 
stopped, even though the aqueous chemistry conditions ( $\mathrm{pH}$ and ionic strength) remained unchanged. Approximately half of the clay-size fraction in the sediment was released in the single sharply defined plume. The mobilized colloids were mainly goethite and kaolinite with their fraction ratios from $2: 1$ to $1: 1$. The released colloids had negative surface charges and their mean particle sizes were primarily in a range of $200-470 \mathrm{~nm}$, and the particles were less than $1000 \mathrm{~nm}($ or $<1 \mu \mathrm{m})$.

Although colloid mobilizations in subsurface zones can be very complex and affected by many factors, electrostatic forces inherent to the different minerals appears to be the controlling mechanism in this system. It was shown in this work that at $\mathrm{pH} 5.5$, goethite has a positive surface charge, whereas quartz and kaolinite have negative surface charges. Nano-goethite acts as a cementing agent, holding the kaolinite on the sand surfaces due to electrostatic attraction. However, at the high $\mathrm{pH}$ plume front, the SRS sand grains, kaolinite and goethite all have negative surface charges, and the nano-size goethite and kaolinite are mobilized due to their electrostatic repulsion. With dilution of the undiluted leachate solution, more pore volumes of leachate were required to promote colloid release (simulating distance from the cementitious source term), and once the colloids were released they formed a broad, less well-defined peak, with fewer colloids; essentially no colloids were mobilized at the 1:1000 dilution. With $\mathrm{pH}$ adjustment for the 1:10 diluted CLS solutions (again, simulating distance from the cementitious source term), even more pore volumes of leachate were required to promote colloid release, and progressively fewer colloids were mobilized, until no colloids were detected at $\mathrm{pH} \leq$ 9.87. In both cases, the possibility of colloid mobilization was dependent on the surface charge of goethite in the corresponding solutions.

Together this data demonstrates that in situ homogeneous precipitation, which is simply the mixing of cement leachate with SRS groundwater (without a solid present), is not likely to result in the formation of a large amount of precipitated solid phases.

Additionally, it was shown that a SRS subsurface system is not spontaneously dispersive, meaning that the subsurface clays tend to remain immobile due to natural electrostatic forces. However, when a cementitious leachate $(\mathrm{pH} 12.80$ to $\mathrm{pH} \sim 8)$ comes in contact with the sediment, dispersion will occur as a sharp peak, containing a relatively high percentage of the clay-size particles in the sediment $(\sim 13 \%)$. Subsequently, few colloids enter the mobile phase, although the aqueous chemical conditions of the system remain unchanged. Finally, within the cementitious plume we collected in situ precipitates, specifically a $\mathrm{Na}-\mathrm{CO}_{3}$ phase. Once the cement leachate was diluted 1000 times with a groundwater or if the $\mathrm{pH}$ dropped below $\sim 8$, colloid release was undetectable. 


\section{TABLE OF CONTENTS}

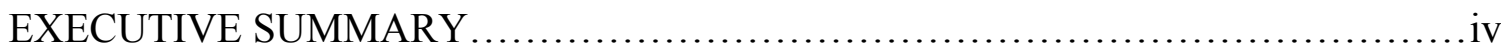

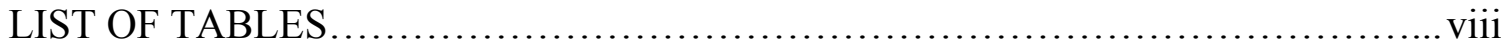

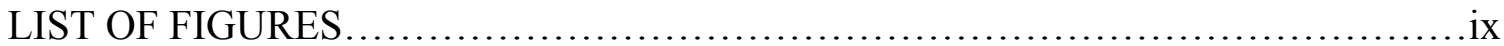

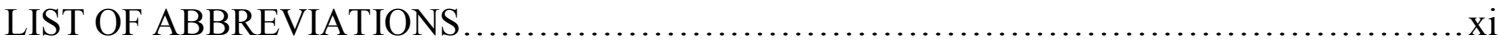

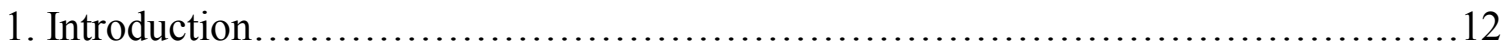

1.1 Colloid dispersion studies on the SRS ................................ 13

1.2 Objectives and scope............................................... 14

2. Materials and Methods....................................................... 14

2.1 Materials.................................................................. 14

2.1.1 SRS groundwater.............................................. 14

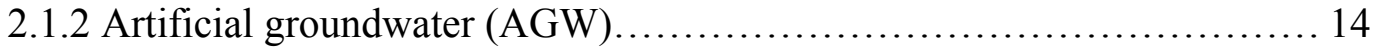

2.1.3 Cement leachate simulant (CLS) ................................... 14

2.1.4 Genuine cement leachate (GCL) .................................. 15

2.1.5 SRS sandy sediment............................................ 15

2.1.6 Other minerals - kaolinite and goethite............................ 17

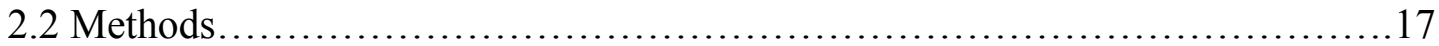

2.2.1 Titration experiment............................................. 17

2.2.2 Column experiment.............................................. 17

2.2 .3 Turbidity........................................................ 18

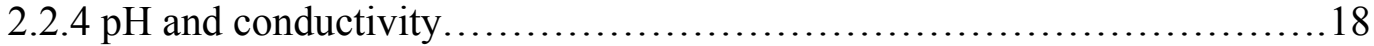

2.2.5 Particle size distribution (PSD) and zeta potential....................... 19

2.2.6 Inductively coupled plasma optical emission spectroscopy (ICP-OES).... 19

2.2.7 X-ray diffraction (XRD) .......................................... 19

2.2.8 Scanning electron microscopy (SEM) and energy dispersive X-ray

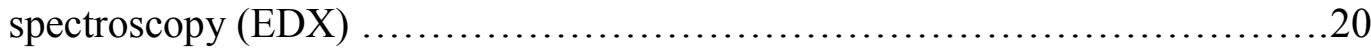

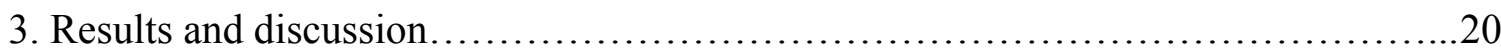

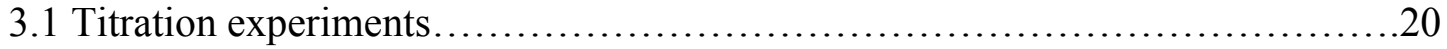

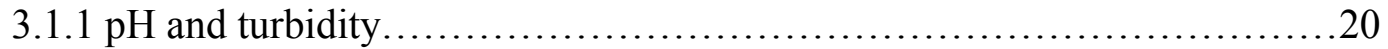

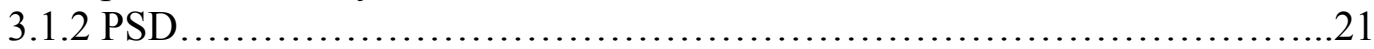

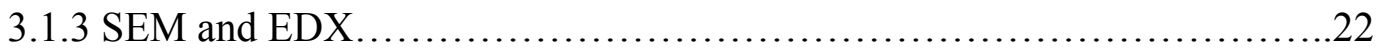

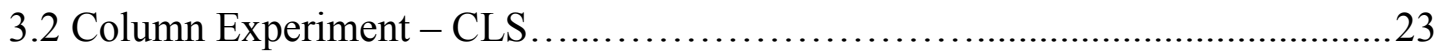

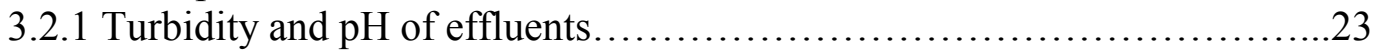

3.2.1.1 CLS and its diluted solutions.................................. 23

3.2.1.2 1:10 diluted and $\mathrm{pH}$ adjusted CLS solutions....................26

3.2.2 Chemical compositions of effluents................................ 28

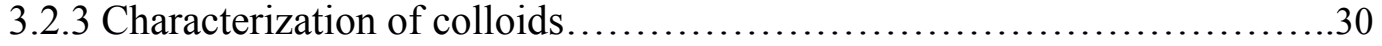




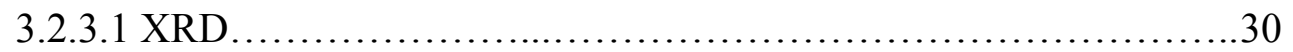

3.2.3.2 SEM and EDX........................................... 31

3.2.3.3 PSD and Zeta potential...................................... 33

3.3 Column Experiment - GCL......................................... 38

3.3.1 Column experiment............................................. 38

3.3.2 Chemical compositions of effluents...............................40

3.3.3 Characterization of colloids....................................... 41

3.3.3.1 XRD.................................................... 41

3.3.3.2 SEM and EDX............................................. 42

3.3.3.3 PSD and Zeta potential................................... 44

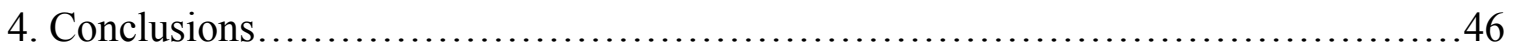

5. Reference............................................................ 47 


\section{LIST OF TABLES}

Table 1. Characteristics of SRS groundwater (FAW05, FPZ6A), AGW, CLS and GCL 15

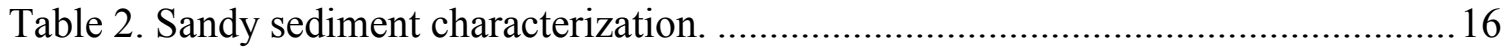

Table 3. Characteristics of effluent samples collected from CLS passing through the SRS

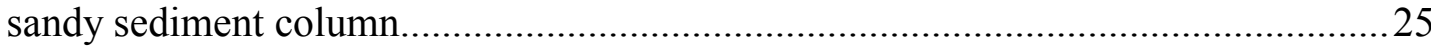

Table 4. Mean particle size and Zeta potential of colloids in the direct effluents of CLS

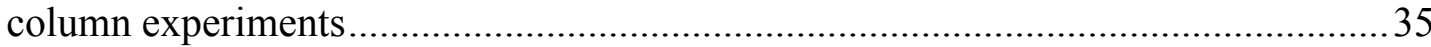

Table 5. Characteristics of collected samples in SRS sandy sediment column by undiluted

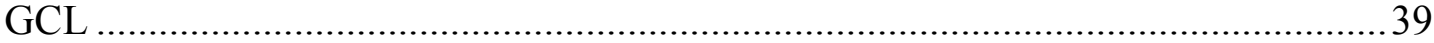

Table 6. Mean particle size and Zeta potential of colloids in the direct effluents of undiluted GCL column experiments..... 


\section{LIST OF FIGURES}

Figure 1. XRD patterns of (A) SRS sandy sediment, (B) its associated $<2 \mu$ m dispersible clay fraction and (C) the $<2 \mu \mathrm{m}$ dispersible clay fraction after heating to $550{ }^{\circ} \mathrm{C}$ for 1 hour. These XRD patterns show that the $<2 \mu \mathrm{m}$ dispersible clay fraction are enriched in kaolinite, goethite, and anatase, with respect to the sediments that contain primarily quartz kaolinite, and HIV (shown as muscovite) ............................ 16

Figure 2. SEM (A) and EDX (B) of air-dried SRS sandy sediment ............................ 17

Figure 3. $\mathrm{pH}$ increase as a result of titrating CLS with three SRS groundwaters............21

Figure 4. Turbidity (NTU) changes from titrating CLS with three SRS groundwaters. ..21

Figure 5. SEM and EDX of SRS groundwater FAW05 titrated with CLS. ....................22

Figure 6. SEM and EDX of SRS groundwater FPZ6A titrated with CLS. Green scale bar in SEM image is 30 micron............................................. 23

Figure 7. Turbidity (A) and $\mathrm{pH}(\mathrm{B})$ of the effluents from column experiments of CLS (red) and its diluted solutions (green for 1:10; blue for 1:100; pink for 1:1000) vs the number of pore volumes. In Figure 7A, the solid lines represent the baseline, the turbidity of the peak and the last data point was indicated, for each column experiment.

Figure 8 . The maximum turbidity of the collected effluent samples against the $\mathrm{pH}$ and conductivity of CLS and its diluted solutions.

Figure 9. Turbidity (A) and $\mathrm{pH}(\mathrm{B})$ of the effluents from column experiments of 1:10 diluted and $\mathrm{pH}$ adjusted CLS solutions versus the number of pore volume. In Figure 9A, the solid lines represent the baseline, the turbidity of the peak and last data point were indicated, for each column experiment.

Figure 10. The maximum turbidity of the collected samples against the $\mathrm{pH}$ and conductivity of 1:10 diluted and $\mathrm{pH}$ adjusted CLS solutions

Figure 11. Breakthrough curves of major cations in the effluents of sandy sediment column by CLS ( $\mathrm{pH} 12.78$ )

Figure 12. XRD patterns of air-dried colloids from the column study by CLS 30

Figure 13. SEM and EDX of air-dried colloids from the SRS sandy sediment column by CLS. The sample identification labels, A7, A8, A9 and A10, are the same as shown in Figure 7

Figure 14. Mean particle size (green squares) and Zeta potential (red circles) of collected colloid suspensions. A7 to A12 are the sample labels as in Figure 1.

Figure 15. Zeta potentials of SRS sandy sediment (red circles), kaolinite (green squares) and goethite (pink diamonds) in (A) CLS and its diluted solutions and (B) 1:10 
diluted and $\mathrm{pH}$ adjusted CLS solutions. Zeta potentials of the minerals in undiluted CLS were measured using ZetaPals at Brookhaven Instruments, Inc. All other were

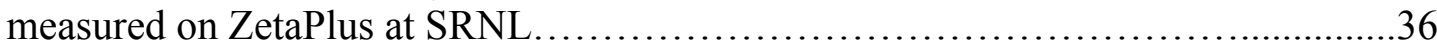

Figure 16. Schematic diagram showing mobilization mechanism of nano goethite and kaolinite in SRS sandy sediment column by cement leachate stimulant (B), in comparison with artificial groundwater (A). Experimental turbidity vs. pore volume of AGW (C) and cement leachate stimulant (CLS) (D). (Note difference between y-

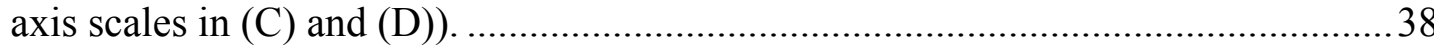

Figure 17. Turbidity (red circles) and $\mathrm{pH}$ (green squares) breakthrough curves in the SRS sandy sediment columns by undiluted GCL (A) and 1:10 diluted GCL solution (B) 40

Figure 18. Breakthrough curves of major cations in the effluents of sandy sediment column by undiluted GCL ( $\mathrm{pH} 12.30)$....

Figure 19. XRD patterns of mobile colloids from sandy sediment column by undiluted GCL

Figure 20. SEM and EDX of air-dried colloids from the SRS sandy sediment column by undiluted GCL. The sample identification labels, 1-9 and 1-10, are the same as shown in Figure 17A 


\section{LIST OF ABBREVIATIONS}

$\begin{array}{ll}\text { AD } & \text { Analytical Development } \\ \text { AGW } & \text { Artificial groundwater } \\ \text { C } & \text { Conductivity } \\ \text { CLS } & \text { Cement leachate simulant } \\ \text { DI } & \text { Deionized water } \\ \text { EDX } & \text { Energy dispersive X-ray spectroscopy } \\ \text { EPA } & \text { Environmental Protection Agency } \\ \text { GCL } & \text { Genuine cement leachate } \\ \text { HIV } & \text { Hydroxyl-interlayered vermiculite } \\ \text { ICP-OES } & \text { Inductively coupled plasma-optical emission spectrometry } \\ \text { NTU } & \text { Nephelometric Turbidity Unit } \\ \text { OM } & \text { Organic matters } \\ \text { PA } & \text { Performance assessment } \\ \text { PSD } & \text { Particle size distribution } \\ \text { PV } & \text { Pore volume } \\ \text { QA } & \text { Quality assurance } \\ \text { QC } & \text { Quality control } \\ \text { SEM } & \text { Scanning electron microscopy } \\ \text { SRNL } & \text { Savannah River National Laboratory } \\ \text { SRS } & \text { Savannah River Site } \\ \text { XRD } & \text { X-ray diffraction } \\ \text { ZPC } & \text { Zero point of charge } \\ & \end{array}$




\section{Introduction}

Colloids are finely divided particles of approximately 1 to 1,000 nanometers in size that are dispersed within a continuous medium in a manner that prevents them from being filtered easily or settling rapidly. Naturally occurring colloids (e.g., silicate clays, Fe and $\mathrm{Al}$ oxides and hydroxides, mineral precipitates, humic materials, microorganisms) are ubiquitously present in subsurface formations. They are formed in situ through geochemical alteration of primary minerals (McCarthy and Zachara, 1989) or the mobilization of colloids, nano-size particles from the solid matrix in subsurface systems (Grolimund and Borkovec, 2006). It is important to distinguish between immobile and mobile colloids, the latter is a potential vector for transporting contaminants in the subsurface and refers to the particle sizes of $<1 \mu \mathrm{m}$, and frequently $<0.3 \mu \mathrm{m}$ (McCarthy and Degueldre, 1993). Colloids in an aquifer may contain contaminants, and they may be the correct size, but remain immobile due to other restrictions, such as coatings, cementing agents, pore size distribution, etc.

Natural colloids are involved in many important processes in the subsurface zone. For example, their generation, mobilization and subsequent transport represent a possible mechanism for structure formation, clogging and structural changes of subsurface porous media, or colloid-enhanced transport of contaminants. Due to their importance, mobilization and transport of colloidal particles in the subsurface environments have been studied to some extent (Bates et al., 1992; Bradford and Torkzaban, 2008; Bunn et al., 2002; Contardi et al., 2001; Crist et al., 2005; DeNovio et al., 2004; Grolimund et al, 1998; 2001; Kaplan et al., 1993; 1996; Kretzschmar et al., 1999; McCarthy and Degueldre, 1993; McCarthy and McKay, 2004; Moridis, et al., 2003; Petosa et al., 2010; Roy and Dzombak, 1996; Ryan and Elimelech, 1996; Ryan and Gschwend, 1994a; 1994b; Seaman and Bertsch 2000; Seaman et al., 1995; 1997; 2007; Sen, 2011; Sen and Khilar, 2006, Wan and Wilson, 1994a; 1994b; Zhuang et al., 2004; 2005). The mobilization of colloids in porous media and subsurface environments is very complex. However, the previous studies, largely based on model systems and relatively scarcely on natural subsurface samples, can lead to several general conclusions (1) lowering the ion strength usually enhances colloidal particle release; (2) the colloid release process strongly depends on the solution chemistry; in particular, monovalent counter ions (e.g., $\mathrm{Na}^{+}$) promote this process more effectively; (3) in systems with $\mathrm{pH}$ dependent surface charge (e.g., the SRS sediments), colloid release is influenced by $\mathrm{pH}$; and, (4) higher flow rates lead to increase the colloid releases (Kaplan et al., 1993; Ryan and Elimelech, 1996).

Recent studies have also shown that toxic and radioactive trace metals in soils, groundwater, rivers and lakes can be carried and transported by mobile colloidal particles (Grolimund and Borkovec, 2005; Kaplan et al., 1994a; 1995; Kretzschmar, et al., 1999; Kretzschmar and Schafer, 2005; Ouyang et al., 1996; Roy and Dzomback, 1997; Kersting et al., 1999). For colloid-facilitated transport to be significant, three criteria must be met: (1) colloids must be generated; (2) contaminants must associate with the colloids; and (3) 
colloids must be transported through the groundwater or in subsurface environments (McCarthy and Zachara, 1989; Ryan and Elimelech, 1996).

It is well known that the adsorption, ion-exchange, redox and precipitation are major immobilization mechanisms of radionuclides in the subsurface environments (Goldberg et al., 2007; Zachara et al., 2007). The majority of the current Performance Assessment (PA) modeling, including SRS PA modeling, is based on the concept that retardation of contaminants is treated by partitioning of radionuclides or contaminants into a two-phase system - a mobile aqueous phase and an immobile solid. Colloid-facilitated transport of radionuclides has not been incorporated into PA modeling. However, although it is still debatable, more laboratory and even field evidence increasingly indicates that natural colloids (either intrinsic or associated colloids) are potentially playing a role in the transport of radionuclides in the subsurface environments of the DOE sites (Buesseler et al., 2009; Dai, et al., 2002; 2005; Flury et al., 2002; Kaplan et al., 1994b; Wan et al., 2004; Zhuang et al., 2003; Kersting et al., 1999). Despite the potential importance of the particle mobilization, experimental investigations of particle release in natural porous media are relatively scarce, and the detailed mechanisms of release and re-deposition of colloidal particles within natural porous media are poorly understood.

\subsection{Colloid dispersion studies on the SRS}

It is evident that under steady state, natural conditions, essentially no colloids are mobilized. However, once these conditions are upset, such as in a contaminant plume, it is possible that colloid dispersion may occur. Previous laboratory studies conducted with SRS soils have shown the potential for the formation of colloids over an environmentally credible range of aqueous-phase chemistries (Seaman et al., 1994, Newman, 1990). These studies indicated that the stable colloids form at either low or high $\mathrm{pH}$ regimes. The formation of colloids in a low $\mathrm{pH}$ regime was attributed to the displacement of $\mathrm{Al}$ from a metal oxide surface by exchange with solution cations, especially divalent cations. In a high $\mathrm{pH}$ regime, the observed high turbidity, resulting from a high concentration of stable colloids, was related to high sodium ion concentration. Newman (2000) studied the colloid formation of SRS soils over a range of $\mathrm{pH}$ in sodium-based solution chemistry. He found that there was no stable colloid suspension present in the lower $\mathrm{pH}$ range, but a stable colloid suspension formed and the concentration systematically increased with $\mathrm{pH}$. The colloids were mainly kaolinite and their formation was relatively unaffected by the solution chemistry. Kaplan (1993) reported the association of contaminants with stable colloids in a field study at the F-area seepage basins. Serkiz et al. (2000) also studied the effects of solution chemistry ( $\mathrm{pH}$, cation composition and ionic strength), and SRS grout structures on the colloid formation in SRS soils, including the leaching and transport of nuclides from SRS wastes during grout emplacement. They found that the higher $\mathrm{pH}$ solutions resulted in the generation of high concentrations of dispersed colloidal materials. The study also found that the higher proportions of divalent cations (calcium and magnesium) relative to sodium decreased the colloid concentrations, but would not completely stop the generation of colloids. The presence of grout materials in subsurface systems is expected to produce an initial high flux of colloids, which quickly return to low levels indicative of background conditions. 
Concrete has been widely used in below grade vaults or structures constructed for the radioactive waste containment at DOE sites including SRS. It is considered as an inexpensive durable alternative wasteform to vitrified glasses (Chen et al., 2009; Li and Wang, 2006; Milestone 2006). Because of its widespread use, DOE has been evaluating the long term stability and impacts of concrete degradation and leaching on the mobilization of colloids and the colloid-facilitated radionuclide transport.

\subsection{Objectives and scope}

The objective of this study was to determine if cementitious leachate would promote the in situ mobilization of natural colloidal particles from a SRS sandy sediment. The intent was to determine whether cementitious surface or subsurface structure would create plumes that could produce conditions conducive to sediment dispersion and mobile colloid generation. Column studies were conducted and the cation chemistries of influents and effluents were analyzed by ICP-OES, while the mobilized colloids were characterized using XRD, SEM, EDX, PSD and Zeta potential. The mobilization mechanisms of colloids in a SRS sandy sediment by cement leachates were studied.

\section{Materials and Methods}

\subsection{Materials}

\subsubsection{SRS groundwater}

Archived groundwater samples collected in F-area at SRS were used in titration experiments. Groundwater was collected from well FAW05 on 1/8/2009 and from FPZ6A on 11/4/2009. All groundwater samples were filtered through a $0.45 \mu \mathrm{m}$ filter prior to use and stored at $40^{\circ} \mathrm{F}$. Field parameter measurements $(\mathrm{pH}$, Conductivity, and Turbidity) and laboratory chemical constituents measured by ICP-OES of SRS groundwater samples are listed in Table 1.

\subsubsection{Artificial groundwater (AGW)}

The artificial concentrated groundwater stock solution was made based on groundwater monitoring survey results described for uncontaminated background groundwater samples at the SRS (Strom and Kaback (1992): $3.68 \mathrm{gram} / \mathrm{L} \mathrm{CaCl}_{2} \cdot 2 \mathrm{H}_{2} \mathrm{O}, 1.07 \mathrm{gram} / \mathrm{L}$ $\mathrm{Na}_{2} \mathrm{SO}_{4}, 0.40 \mathrm{gram} / \mathrm{L} \mathrm{KCl}, 2.65 \mathrm{gram} / \mathrm{L} \mathrm{NaCl}$, and $5.51 \mathrm{gram} / \mathrm{L} \mathrm{MgCl}_{2} \cdot 6 \mathrm{H}_{2} \mathrm{O}$ dissolved in one liter Deionized Water (DI). Then $1 \mathrm{~mL}$ of the concentrated stock solution was diluted to 1 liter to make the AGW. The $\mathrm{pH}$, conductivity, turbidity and ICP-OES results $(\mathrm{Na}, \mathrm{K}, \mathrm{Ca}, \mathrm{Si}, \mathrm{Al}$ and $\mathrm{Fe}$ ) of $\mathrm{AGW}$ used in the column experiments are given in Table 1 .

\subsubsection{Cement leachate simulant (CLS)}

The CLS was made following Serne et al. (1987): $\mathrm{CaCO}_{3}: 13.7 \mathrm{~g}, \mathrm{Ca}(\mathrm{OH})_{2}: 10.55 \mathrm{~g}$, KOH: $69.3 \mathrm{~g}$, NaOH: $193.57 \mathrm{~g}$ and balance of DI water to make 50 liters. The leachate 
simulant was equilibrated on a shaker for four days. The resulting GCL was filtered using a $0.45 \mu \mathrm{m}$ membrane filter. The $\mathrm{pH}$, conductivity and turbidity of the CLS were measured and its chemical compositions were analyzed using ICP-OES. The results are given in Table 1.

\subsubsection{Genuine cement leachate (GCL)}

Ordinary portland cement was mixed with DI water at the water to cement radio of $0.6: 1$ for hydration and cured for 30 days. The cured cement was crushed to pass a \#12 sieve, $<1.68 \mathrm{~mm}$. 200 gram of the crushed cement was mixed with $2000 \mathrm{ml}$ DI water, which was equilibrated on a shaker for 7 days. $0.45 \mu \mathrm{m}$ filter (Type HA) and vacuum pump were used for filtration to get GCL. The $\mathrm{pH}$, conductivity and turbidity of GCL were measured and its chemical compositions were analyzed using ICP-OES. The results are given in Table 1.

Table 1. Characteristics of SRS groundwater (FAW05, FPZ6A), AGW, CLS and GCL

\begin{tabular}{|l|c|c|c|c|c|c|}
\hline & FAW05 & FPZ6A & AGW & $\begin{array}{c}\text { AGW after 25 } \\
\text { PV in column }\end{array}$ & CLS & GCL \\
\hline $\mathrm{pH}$ & 3.77 & 3.8 & 6.29 & 7.15 & 12.78 & 12.3 \\
\hline $\begin{array}{l}\text { Conductivity } \\
\text { (mS/cm) }\end{array}$ & 0.683 & 1.19 & 0.0259 & 0.024 & 21.79 & 9.75 \\
\hline $\begin{array}{l}\text { Turbidity } \\
(\mathrm{NTU})\end{array}$ & $\mathrm{n} / \mathrm{a}$ & 1.3 & 4.12 & 8.30 & 2.56 & 2.32 \\
\hline $\mathrm{Na}(\mathrm{mg} / \mathrm{L})$ & $116 \pm 11.83$ & & $1.25 \pm 0.03$ & $1.34 \pm 0.04$ & $1830 \pm 141$ & $150.8 \pm 6.3$ \\
\hline $\mathrm{K}(\mathrm{mg} / \mathrm{L})$ & $0.76 \pm 0.11$ & & $0.25 \pm 0.02$ & $0.46 \pm 0.01$ & $760 \pm 5$ & $247 \pm 7$ \\
\hline $\mathrm{Ca}(\mathrm{mg} / \mathrm{L})$ & $4.55 \pm 0.45$ & & $0.93 \pm 0.02$ & $0.95 \pm 0.01$ & $81.2 \pm 4.3$ & $765 \pm 10$ \\
\hline $\mathrm{Si}(\mathrm{mg} / \mathrm{L})$ & $32.8 \pm 3.28$ & & $\mathrm{n} / \mathrm{a}$ & $\mathrm{n} / \mathrm{a}$ & $\mathrm{n} / \mathrm{a}$ & \\
\hline $\mathrm{Al}(\mathrm{mg} / \mathrm{L})$ & $19 \pm 1.9$ & & $\mathrm{n} / \mathrm{a}$ & $\mathrm{n} / \mathrm{a}$ & $\mathrm{n} / \mathrm{a}$ & \\
\hline $\mathrm{Fe}(\mathrm{mg} / \mathrm{L})$ & $0.93 \pm 0.09$ & & $\mathrm{n} / \mathrm{a}$ & $\mathrm{n} / \mathrm{a}$ & $\mathrm{n} / \mathrm{a}$ & \\
\hline
\end{tabular}

\subsubsection{SRS sandy sediment}

Subsurface sandy sediment is a major formation in the lower vadose zone and aquifer at the SRS area (Kaplan 2010). The uncontaminated SRS sandy sediment sample was collected from the field, air-dried and passed through a \#10 sieve, $<2 \mathrm{~mm}$. As shown in Table 2, the major mineral of the SRS sandy sediment is quartz ( 97\%), with $\sim 2 \%$ silt and $\sim 1 \%$ clay (e.g., kaolinite and hydroxyl-interlayered vermiculite (HIV; identified in Figure 1A as muscovite)). A dispersion solution was prepared by adding $10 \mathrm{~mL}$ of $5 \%$ sodium metaphosphate $\left(\mathrm{NaPO}_{3}\right)$ and $10 \mathrm{~mL}$ of $1.0 \mathrm{M} \mathrm{NaOH}$ and the balance of DI to a 1 $\mathrm{L}$ volumetric flask. The air-dried sandy sediment was passed through a $\# 10$ sieve $(<2$ $\mathrm{mm})$, and then the $<2 \mathrm{~mm}$ fraction was further passed through a \#270 sieve $(<53 \mu \mathrm{m})$. A $5 \mathrm{~g}$ aliquot of $<53 \mu \mathrm{m}$ fraction and $35 \mathrm{~mL}$ of dispersion solution were placed in $50 \mathrm{~mL}$ centrifuge tubes, which was shaken overnight at a moderately high shaking speed. After that, the centrifuge tube was placed in a secure place to settle for 1 hour 50 minutes. The 
top $2.5 \mathrm{~mL}$ of the suspension was collected by pipetting and centrifuged to separate colloids from solution (Miller and Miller, 1987). The collected colloids $(<2 \mu \mathrm{m})$ were airdried and identified by XRD as kaolinite and goethite (Figure 1B). The colloids were further heated at $550{ }^{\circ} \mathrm{C}$ for 1 hour, its XRD pattern is shown in Figure 1C. Hematite is dominant in the heated colloid, with a small amount of anatase, because at this temperature $\left(550^{\circ} \mathrm{C}\right)$, goethite transforms to hematite (the transformation temperature is $\sim 220^{\circ} \mathrm{C}$ (Ruan et al., 2001)) and kaolinite is stable until $\sim 410^{\circ} \mathrm{C}$ (Ptáček et al., 2010).

Table 2. Sandy sediment characterization

\begin{tabular}{|l|l|l|l|l|l|}
\hline $\mathrm{pH}$ & $\begin{array}{l}\text { Organic } \\
\text { matter }\end{array}$ & $\mathrm{Fe}$ & Sand/Silt/Clay & $\begin{array}{l}\text { Surface } \\
\text { Area }\end{array}$ & Mineralogy \\
\hline & $(\mathrm{wt}-\%)$ & $(\mathrm{wt}-\%)$ & $(\mathrm{wt}-\%)$ & $\mathrm{m}^{2} / \mathrm{g}$ & XRD $(<2-\mu \mathrm{m})$ \\
\hline $5.10 \pm 0.01$ & $<0.01$ & $0.72 \pm 0.03$ & $97 / 2 / 1$ & 1.27 & $\begin{array}{l}\text { Kaolinite }>\text { goethite }> \\
\text { HIV (no quartz) }\end{array}$ \\
\hline
\end{tabular}

A

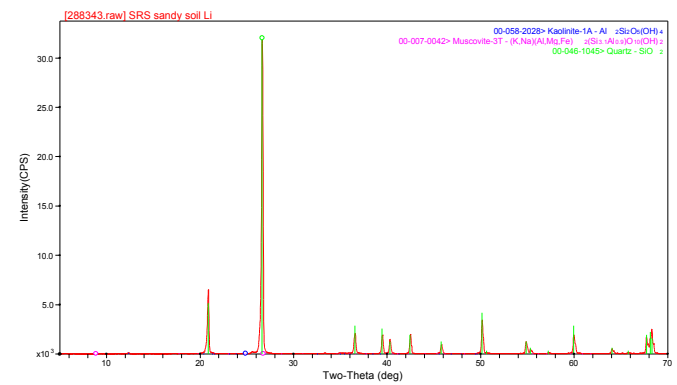

B

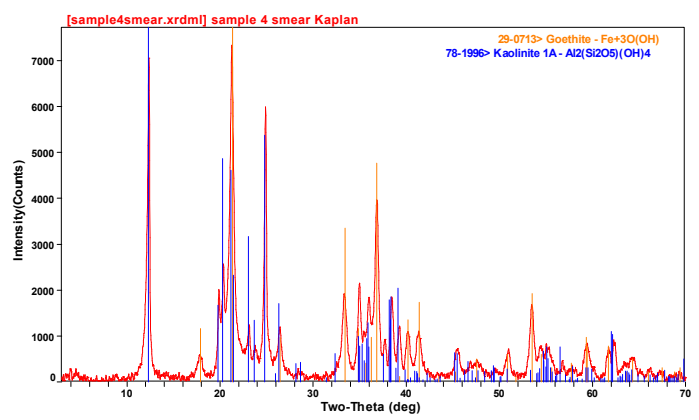

C

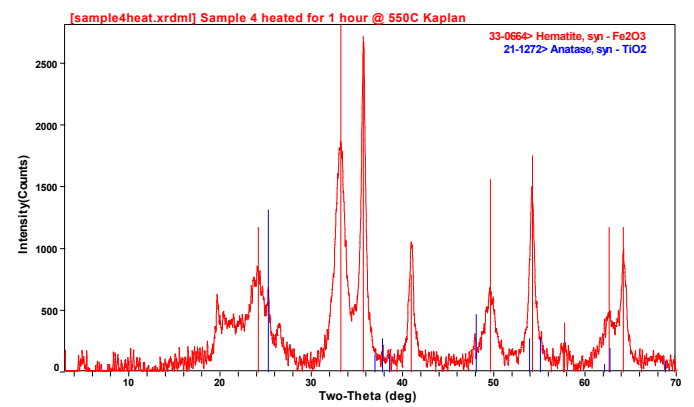

Figure 1. XRD patterns of (A) SRS sandy sediment, (B) its associated $<2 \mu \mathrm{m}$ dispersible clay fraction and $(C)$ the $<2 \mu \mathrm{m}$ dispersible clay fraction after heating to $550{ }^{\circ} \mathrm{C}$ for $1 \mathrm{hour}$. These XRD patterns show that the $<2 \mu \mathrm{m}$ dispersible clay fraction are enriched in kaolinite, goethite, and anatase, with respect to the sediments that contain primarily quartz kaolinite, and HIV (shown as muscovite).

SEM and EDX of air-dried SRS sandy sediment are shown in Figure 2, in which the minerals particles (mostly $<1 \mu \mathrm{m}$ ) are observed to coat on the quartz surface. Steps on the crystal faces of quartz are normally seen in the SEM images as seen here. Aside from $\mathrm{Si}$ and $\mathrm{O}, \mathrm{Fe}$ and $\mathrm{Al}$ are the dominant elements detected in the EDX, indicating the presence 
of Fe- and Al-containing minerals. These are likely nano-size minerals such as goethite, kaolinite and muscovite on the quartz surface.

A

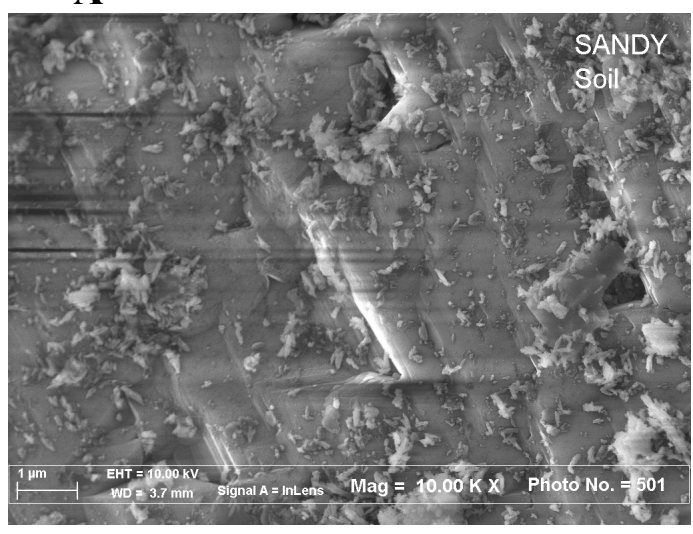

B

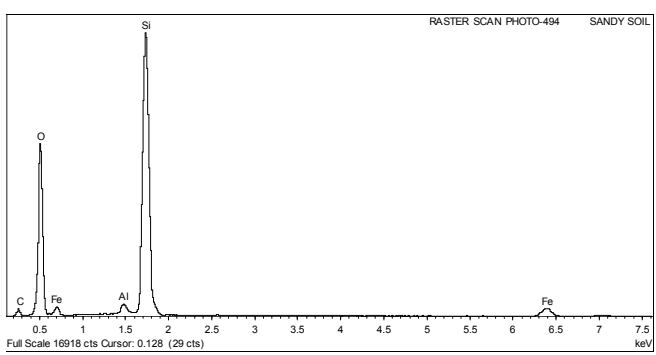

Figure 2. SEM (A) and EDX (B) of air-dried SRS sandy sediment.

\subsubsection{Other minerals - kaolinite and goethite}

In order to better understand better the surface behavior and mobilization mechanisms of colloids from the SRS sandy sediment, the reference minerals - kaolinite $\left(\mathrm{Al}_{2} \mathrm{Si}_{2} \mathrm{O}_{5}(\mathrm{OH})_{4}\right)$ and goethite $(\mathrm{FeOOH})$ were included to comparatively study their surface charge in CLS and GCL.

\subsection{Methods}

\subsubsection{Titration experiment}

For the titration experiments, $250 \mathrm{~mL}$ of SRS groundwater collected from F-Area (FAW05 and FPZ6A) were titrated with cement leachate solution (CLS) using a Jensen Systems Sensolab mini-titrator. Initial experiments measured the $\mathrm{pH}$ changes of the solution to determine the inflection point. The colloids, if any, were expected to form along the $\mathrm{pH}$ frontal boundary. $\mathrm{pH}$ and turbidity measurements were made on subsequent titrations from which the high turbidity samples were selected for PSD measurements on the ZetaPlus and/or ultrafiltered using a Millipore $1 \mathrm{kDa}$ regenerated cellulose ultrafilter in a Amicon stirred cell ultrafiltration apparatus. In selected cases the ultrafilters containing the $>1 \mathrm{kDa}(\sim 1 \mathrm{~nm})$ size fraction were air dried and submitted for SEM and EDX analyses.

\subsubsection{Column experiment}

The polycarbonate columns used in this study were $15 \mathrm{~cm}$ long and $2.54 \mathrm{~cm}$ in inner diameter, corresponding to a volume of $75.97 \mathrm{~cm}^{3}$. Both the ends of each column were 
sealed to retain the sandy sediment by caps with o-rings. The bottom end (input) had a polypropylene membrane screen of $0.45 \mu \mathrm{m}$ to filter any particles present in the incoming solutions, while the top end had a nylon membrane screen of $250 \mu \mathrm{m}$ to allow the passage of mobilized colloids into the test tubes. A dry and homogenized sandy sediment $(\sim 119 \pm$ 1.80 gram) was packed into the column with a bulk density of $1.57 \pm 0.02 \mathrm{gram} / \mathrm{cm}^{3}$. The porosity of the packed sandy sediment was estimated at $27.2 \pm 0.6 \%$ by the amount of water that soaked the whole sandy sediment column. The pore volume for the column was $20.6 \pm 0.5 \mathrm{~mL}$. The incoming solutions were injected upward from the bottom of vertically oriented columns by a peristaltic pump. The flow rate was set at $\sim 1 \mathrm{~mL} / \mathrm{minute}$ for flushing with AGW. However, the flow rate was adjusted to $0.35 \pm 0.01 \mathrm{~mL} / \mathrm{minute}$ for the incoming cement leachates, which corresponds to the Darcy velocity of $\sim 1$ meter/day and the column residence time of $59.0 \pm 1.6$ minutes. Effluents were collected from the top of a column at room temperature into test tubes through a fraction collector. The fraction collector was set to collect one sample for every one quarter of pore volume (PV) (i.e., approximately one sample every $14.75 \pm 1$ minutes). The column experiments were performed in two steps at room temperature. First, AGW was flushed into the column at the flow rate of $\sim 1 \mathrm{~mL} / \mathrm{min}$ for 25 pore volumes before the AGW effluent was collected and its $\mathrm{pH}$, conductivity and turbidity were measured (Table 1). Second, cement leachates were injected into the column at the flow rate of $0.35 \pm 0.01 \mathrm{~mL} /$ minute for up to 25 pore volumes. The $\mathrm{pH}$, conductivity and turbidity of all samples collected during this period were measured within 24 hour of their collection. For the collected samples with a sharp spike in colloid concentrations, the particle size distribution (PSD) and Zeta potential were measured before they were centrifuged at the speed of $10,000 \mathrm{rpm}$ for 30 minutes. After centrifugation, the effluents were filtered through $0.1 \mu \mathrm{m}$ membrane filters and used for ICP-OES analysis to determine the chemical compositions ( $\mathrm{Na}, \mathrm{K}, \mathrm{Ca}, \mathrm{Si}$, $\mathrm{Al}, \mathrm{Fe}$ ), while the colloidal particles were air-dried and characterized by XRD, SEM and EDX.

\subsubsection{Turbidity}

The turbidity (surrogate for relative concentration of suspended colloidal particles in liquids) was measured using Hach model 2100AN turbidimeter. The turbidity of all collected samples from column experiments was measured within 24 hours. The samples were agitated for 30 seconds before the measurement of turbidity. A portion of colloidal suspension was diluted with DI water in the Hach specified glass bottle and the measured turbidity was converted based on the dilution ratio accordingly.

\subsection{4 $\mathrm{pH}$ and conductivity}

$\mathrm{pH}$ and conductivity were measured using Radiometer Copenhagen PHM $95 \mathrm{pH}$ meter and CDM 210 conductivity meter (CDM $241-9$ probe) at room temperature, respectively. The $\mathrm{pH}$ meter was calibrated daily and the conductivity meter was calibrated monthly.

\subsubsection{Particle size distribution (PSD) and zeta potential}


The PSD and Zeta potential of the colloids and minerals were measured using ZetaPlus (Brookhaven Instruments Corp) at SRNL if not otherwise specified. The ZetaPlus required very low particle concentration in diluents and working solutions of conductance $<10 \mathrm{mS} / \mathrm{cm}$. It did not work well for colloids in the undiluted CLS that had a conductance of $21.79 \mathrm{mS} / \mathrm{cm}$, and worked marginally for colloids in the undiluted GCL that had a conductance of $9.75 \mathrm{mS} / \mathrm{cm}$. The colloidal suspensions collected from the column experiments were diluted with DI water in cuvettes. The particle size distribution (PSD) measurement was set for 5 runs for a total of 5 minutes. The reported data are the average of the 5 measurements. The zeta potential was set to have 10 measurements and the reported data are the average of the 10 measurements. The $\mathrm{pH}$ of the working solution with colloids in the cuvettes was measured, which is slightly lower than that of the corresponding undiluted effluents. The Zeta potential of ground SRS sandy sediment, kaolinite and goethite in the diluted CLS solution (1:10, 1:100, 1:1000 dilutions), 1:10 diluted CLS solutions with $\mathrm{pH}$ adjustment, AGW, and undiluted GCL (conductivity of $9.75 \mathrm{mS} / \mathrm{cm}$ ) were measured using ZetaPlus. In addition, the Zeta potential of ground SRS sandy sediment, kaolinite and goethite in contact with CLS (conductivity of 21.79 $\mathrm{mS} / \mathrm{cm}$ ) and GCL (conductivity of $9.75 \mathrm{mS} / \mathrm{cm}$ ) were also measured with titration using ZetaPals at Brookhaven Instrument Corp.

\subsubsection{Inductively coupled plasma optical emission spectroscopy (ICP-OES)}

The effluents from the sandy sediment columns in contact with undiluted CLS (pH 12.78) were chosen to study the cation compositions of the effluents. The collected effluents from column studies were kept at room temperature for 45 days before they were centrifuged at 10,000 rpm for 30 minutes. The top clear liquid in the test tube was extracted by a syringe and passed through a $0.1 \mu \mathrm{m}$ membrane filter to obtain the liquid portion of the effluents. The clear liquid effluents were acidified using a $2 \%$ nitric acid solution. The major cation compositions ( $\mathrm{Na}, \mathrm{K}, \mathrm{Ca}, \mathrm{Si}, \mathrm{Al}, \mathrm{Fe}$ ) in the effluents were analyzed by inductively coupled plasma optical emission spectrometry (ICP-OES) (Optima 4300 DV; Perkin-Elmer Corp., Norwalk, CT) following the QA/QC protocols outlined in EPA Method 6010C (Rev. 3; 2007) using Yttrium (Y) as an internal standard.

\subsubsection{X-ray diffraction (XRD)}

X-ray diffraction data of the air-dried colloids were collected on a Bruker D8 X-ray Diffractometer by step scanning over the $2 \theta$ ranges of $5-70^{\circ}$ with a step size of $0.02^{\circ}$ (SRNL, Analytical Development Directorate). $\mathrm{Cu} \mathrm{K}_{\alpha} \mathrm{X}$-ray was used as radiation source. The source powder was $45 \mathrm{kV}$ and $40 \mathrm{~mA}$. The sandy sediment sample $>2 \mu \mathrm{m}$ in particle size were ground for five minutes in an agate mortar and pestle. Ethanol was added as a lubricant to facilitate grinding and to minimize the alteration of heat-sensitive minerals. This process reduced the average particle size to $<2 \mu \mathrm{m}$. A plate glass slide and a dwell time of one second were used for XRD data collection of the sandy sediment sample. The samples were just ground slightly and placed on the back of a zero background quartz slide. The XRD data for all samples has a dwell time of ten seconds. Search-match identification of all the mineral phases was performed with Jade software (Version 9.1.0) from Materials Data Inc. 


\subsubsection{Scanning electron microscopy (SEM) and energy dispersive X-ray spectroscopy (EDX)}

The SEM and EDX of the air-dried colloids were collected at SRNL Analytical Development Directorate. The SEM used was the Carl Zeiss NTS model Sigma VP, equipped with X-Max EDX detector (Oxford Instruments). The experimental parameters are shown on the corresponding SEM images: Scale bar indicates distance, EHT is the accelerating voltage of the electrons, WD is the working distance (i.e. distance from pole piece to sample), Signal A is the detector used to take the image: SE2 and InLens are secondary electron detectors, CZ BSD is a backscatter electron detector, Photo No. is a number used to track photographs, and Mag is the magnification of the image.

\section{Results and Discussion}

\subsection{Titration experiments}

\subsection{1. $\mathrm{pH}$ and turbidity}

As expected, both the $\mathrm{pH}$ and turbidity of SRS groundwater titrated with CLS show an increase with volume of titrant added (Figures 3 and 4). The chemical compositions of the groundwater used in these experiments are presented in Table 1. FAW05 and FPZ6A were collected from approximately $24 \mathrm{~m}$ and $0.1 \mathrm{~m}$ below surface, respectively. FAW05 and FPZ6A had the same starting $\mathrm{pH}$ of 3.8 (Table 1). Very little titrant $(<1 \mathrm{~mL}$ to $250 \mathrm{~mL}$ groundwater) is needed to show an increase in $\mathrm{pH}$ of the titrated solution. An increase in the turbidity, a proxy for colloidal concentration, is seen with the addition of titrant $(2 \mathrm{~mL}$ of titrant in $250 \mathrm{~mL}$ groundwater) corresponding to a $\mathrm{pH}>8$. Though these trends are evident, the magnitude of the turbidity is so low $(<5 \mathrm{NTU})$ that it indicates very little colloidal material is generated through this pathway. To put this turbidity value in perspective, in Section 3.2, turbidity values will be measured in column studies $>10,000$ NTU. FAW05 is a more buffered solution because it required more titrant (base) be added to increase the $\mathrm{pH}$. 
Rev. 0

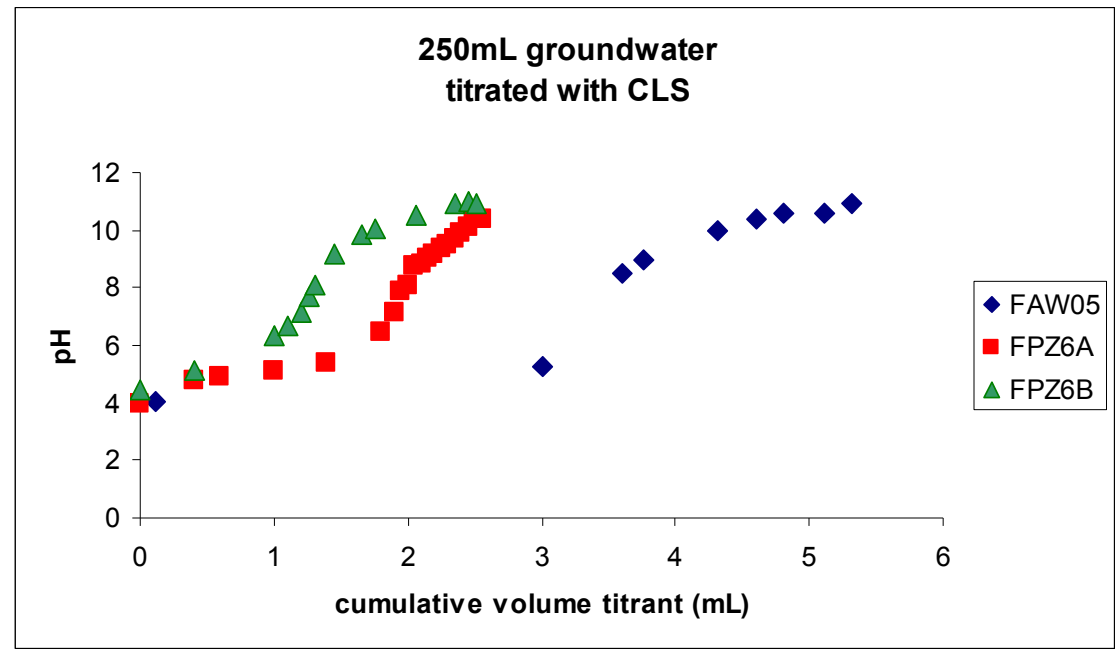

Figure 3. pH increase as a result of titrating CLS with three SRS groundwaters

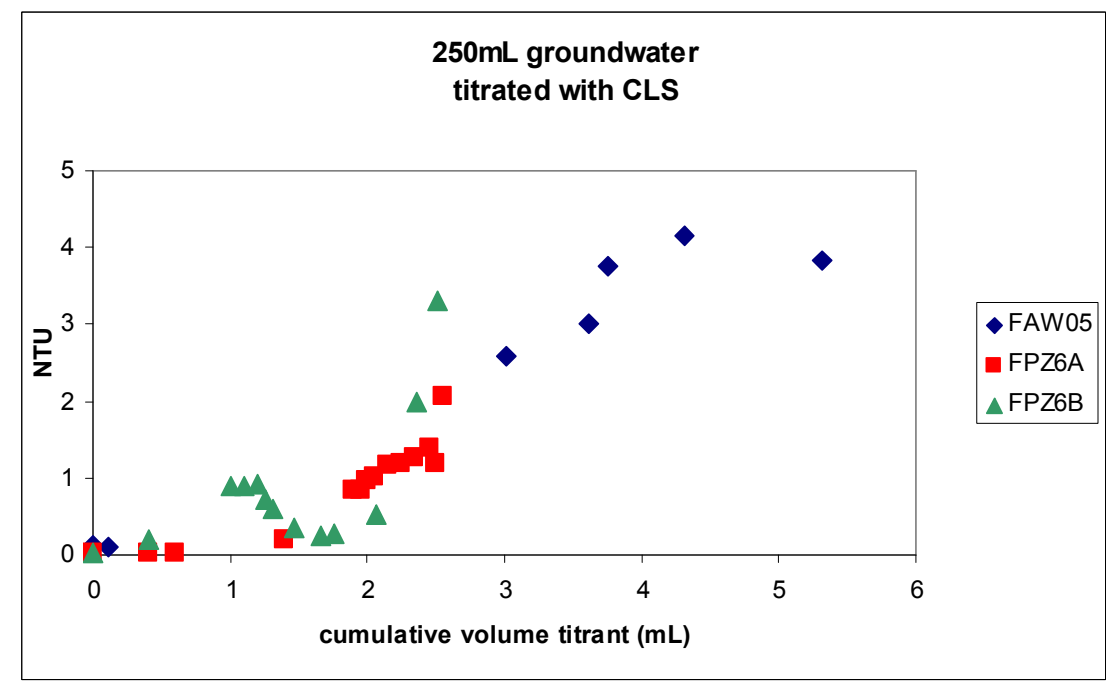

Figure 4. Turbidity (NTU) changes from titrating CLS with three SRS groundwaters.

\subsubsection{PSD}

Due to the low turbidity measurements from the titration experiments, ultrafiltration was employed as a means of concentrating colloidal matter to determine particle size. Attempts to measure particle size were unsuccessful in that the fraction retained on the $1 \mathrm{kDa}$ filter had mean particle sizes greater than the $6 \mu \mathrm{m}$ limit of the instrument. 


\subsubsection{SEM and EDX}

Though the colloidal concentration of SRS groundwater was low, colloidal material was collected on a $1 \mathrm{kDa}$ ultrafilter and SEM and EDX analyses was performed on the filters. Figure 5 shows the EDX results from a blank spot on the filter for a baseline for the groundwater sample FAW05. The baseline (SPOT-2) contains primarily $\mathrm{C}$ and $\mathrm{O}$ and is attributed to the regenerated cellulose composition of the filter. SPOT-1 of the same filter contains primarily $\mathrm{Si}, \mathrm{Al}$ and $\mathrm{O}$, but contains smaller amounts of $\mathrm{Fe}, \mathrm{Ca}, \mathrm{Mn}$ and $\mathrm{K}$. Figure 6 shows selected results from groundwater sample FPZ6A titrated with CLS. Si and $\mathrm{Al}$ dominate in one particle but smaller amounts of $\mathrm{K}, \mathrm{Ca}, \mathrm{Na}, \mathrm{Mg}$, and $\mathrm{Fe}$ are present. Another particle type shows Fe as dominant with small amounts of Cr. However, the green scale bar in both figures represents $30 \mu \mathrm{m}$ and as such these "spots" are in fact particles and not at all in the colloidal size range.

FAW05 titrated with CLS
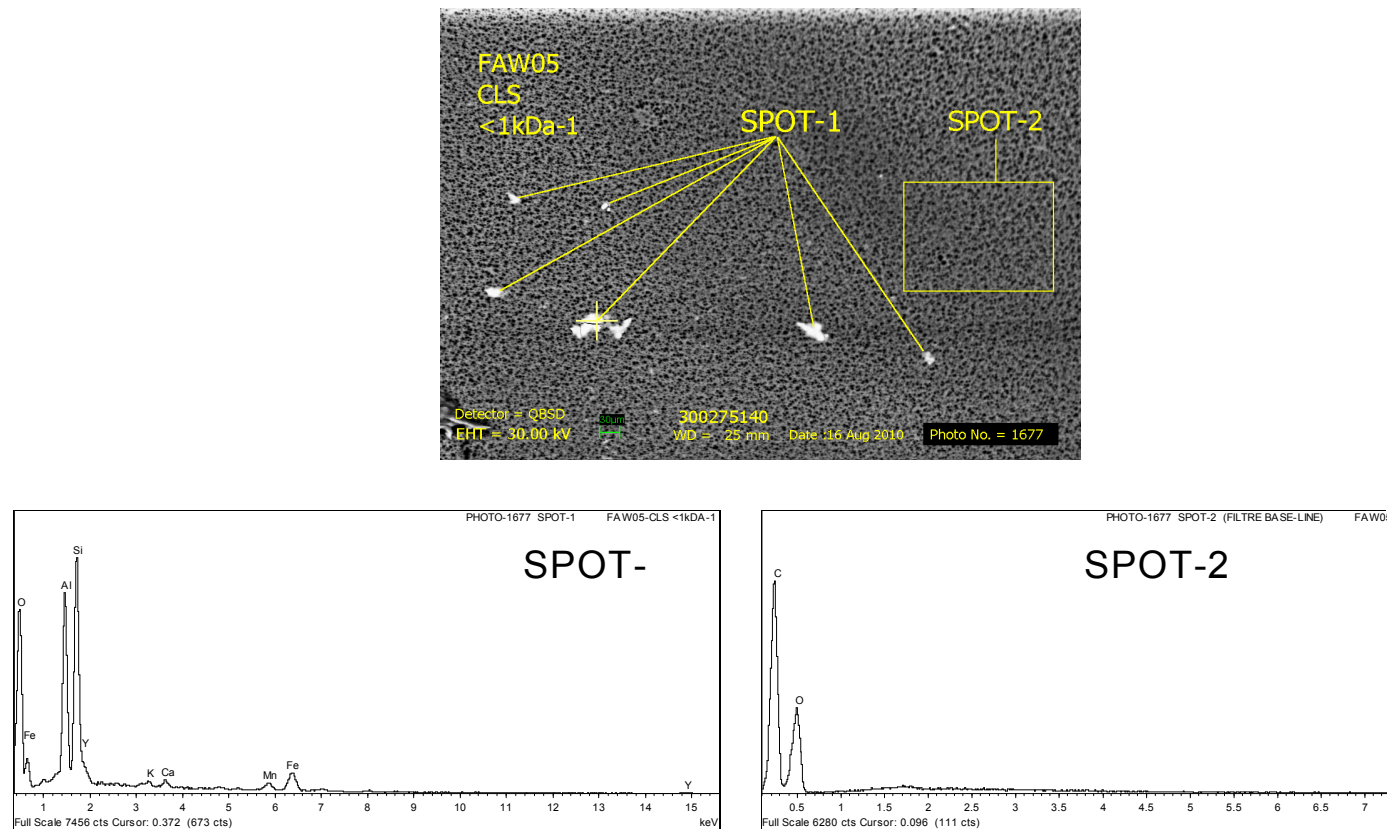

Figure 5. SEM and EDX of SRS groundwater FAW05 titrated with CLS. 


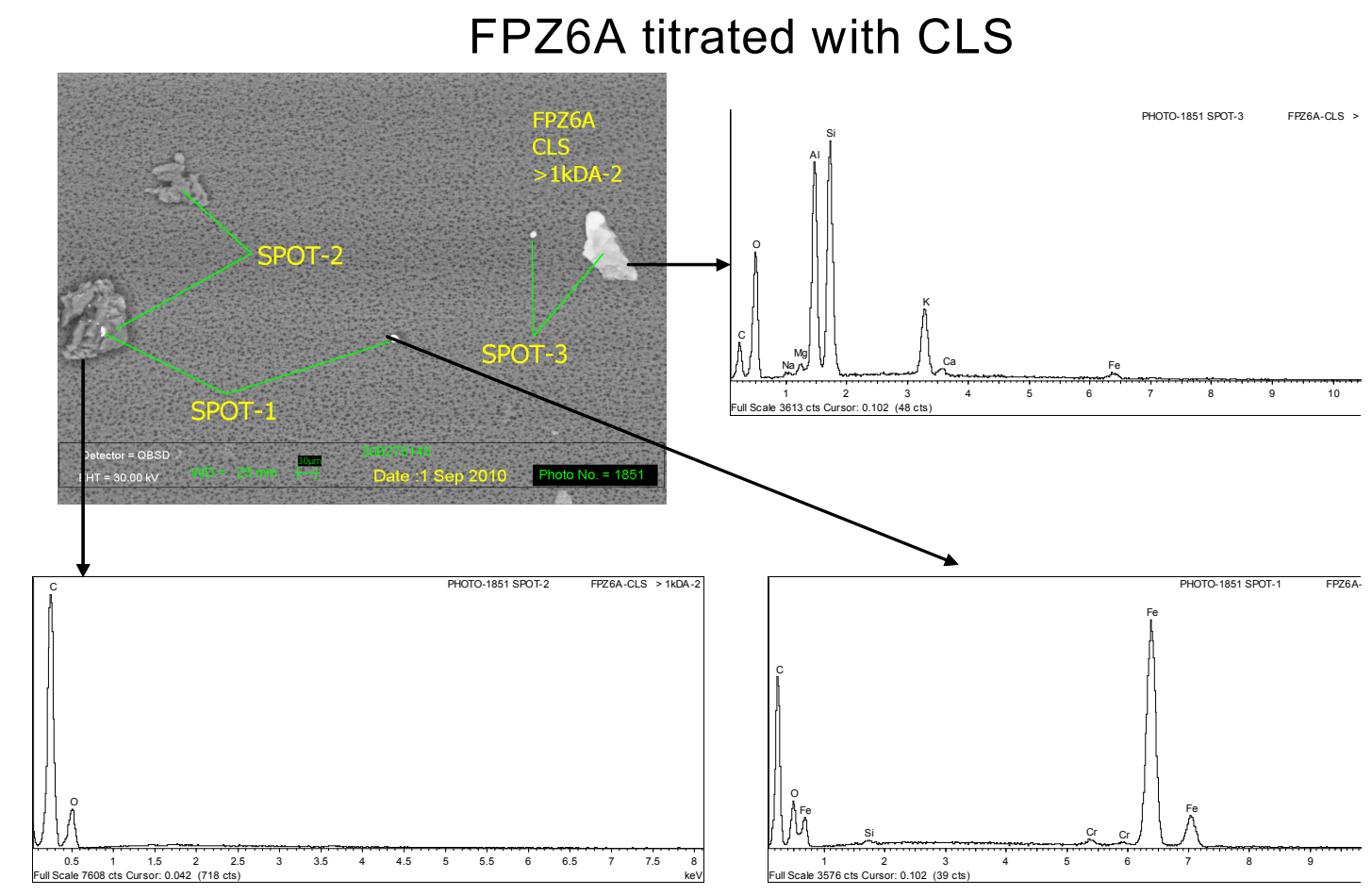

Figure 6. SEM and EDX of SRS groundwater FPZ6A titrated with CLS. Green scale bar in SEM image is $\mathbf{3 0}$ microns.

\subsection{Column Experiment - CLS}

\subsubsection{Turbidity and $\mathrm{pH}$ of effluents}

\subsubsection{CLS and its diluted solutions}

The CLS was diluted with DI water at the radios of $1: 10,1: 100$ and 1:1000. The turbidity (A) and $\mathrm{pH}$ (B) breakthrough curves of the sandy sediment columns with CLS and its diluted solutions are presented in Figure 7 and Table 3. The turbidity, $\mathrm{pH}$ and conductivity measurements were performed as soon as effluent samples were collected (within 24 hours). For the undiluted CLS (red curves), A7 (PV = 1.75), A8 ( $\mathrm{PV}=2.0$ ), $\mathrm{A} 9(\mathrm{PV}=2.25)$ and $\mathrm{A} 10(\mathrm{PV}=2.5)$ in the turbidity breakthrough curve are the sample identifications and will be referred to in the following sections on chemical compositions of effluents and the characterization of colloids. The colloids in effluents emerged from the column after $1.75 \mathrm{PV}$, and then rapidly maximized at $\sim 2.0 \mathrm{PV}$ of the leachate simulant injection. This was expected because the column was flushed by AGW for 25 PV and supposed to be saturated; in addition, the inner volume of tubes that connected between the stock solution tank and the bottom end of column and between the top end of column and fraction collector test tube was about $17.6 \mathrm{~mL}$, almost equivalent to one PV of the column $(20.6 \mathrm{~mL})$. Therefore, the first $1.75 \mathrm{PV}$ effluent fraction contained primarily the displaced AGW, which were characterized by its $\mathrm{pH} 7.15$ and turbidity 8.30 NTU (Table 1), with some influence from mixing of the displaced AGW with CLS (e.g., 
$\mathrm{pH}$ increase). The plume front location ( $\sim 2 \mathrm{PV})$ can be determined by the emerging of turbidity maximum and the inflection point of $\mathrm{pH}$ of the solution breakthrough, in good agreement with the pore water displacement. No $\mathrm{pH}$ reduction prior to the plume front was observed for the undiluted CLS. The colloids first emerged from the column at the $\mathrm{pH}$ of 11.51 (at 1.75 PV) and maximized at $\mathrm{pH} 12.28$ (at 2.00 PV). The maximum turbidity was $\sim 70571 \mathrm{NTU}$, and the collected suspension samples are very brownish in appearance. After that, the mobilization of colloids reduced dramatically by $3.00 \mathrm{PV}$, but a very minimal amount of colloids were mobilized, as indicated by the appearance of collected samples and the very low turbidity until $\sim 7 \mathrm{PV}$ while the $\mathrm{pH}$ increased toward that of undiluted CLS (pH 12.78). After $7 \mathrm{PV}$, the collected samples were colorless with turbidity close to 2-3 NTU.

For 1:10 diluted CLS solution, the colloids first emerged from the column at the $2.25 \mathrm{PV}$ and $\mathrm{pH} 9.28$, and maximized at the $2.5 \mathrm{PV}$ and $\mathrm{pH} 10.16$. The maximum turbidity was $55186 \pm 12270 \mathrm{NTU}$, and the collected samples are very brownish in appearance. However, the mobilization of colloids reduced slower compared to that of the undiluted CLS, so that the plume front was shown to have a tail up to $8 \mathrm{PV}$; in fact, the colloids continued being mobilized until $25 \mathrm{PV}$ in our experiment, as indicated by the lightly brownish suspension samples and the turbidity of $322 \mathrm{NTU}$. The $\mathrm{pH}$ breakthrough curve indicated the $\mathrm{pH}$ reduction prior to the plume front, and the inflection point occurred at $\sim 4.5 \mathrm{PV}$, and the $\mathrm{pH}$ at the end of our experiment (24.5 PV) was 11.27, slightly lower than that of the 1:10 diluted CLS solution ( $\mathrm{pH} 12.02)$.

In a similar trend, the colloids first emerged from the column at the $6.25 \mathrm{PV}$ and $\mathrm{pH} 7.63$ and maximized at the $7.25 \mathrm{PV}$ and $\mathrm{pH} 8.66$ for 1:100 diluted CLS solution. The maximum turbidity was $15203 \mathrm{NTU}$, and the collected samples are very brownish in appearance. However, the mobilization of colloids reduced even slower compared to that of the 1:10 diluted CLS solution, so that the plume front had a very broad tail until the end of our column experiment at $23 \mathrm{PV}$, at which the colloids continued being mobilized, as indicated by the lightly brownish suspension effluents and the turbidity of 1227 NTU. The $\mathrm{pH}$ breakthrough curve also indicated the $\mathrm{pH}$ reduction prior to the plume front, and the inflection point might occur at $\sim 9.5 \mathrm{PV}$. But even after that, $\mathrm{pH}$ kept increasing at a slower pace and the $\mathrm{pH}$ at the end of our experiment (23 PV) was 10.38, slightly lower than that of the 1:100 diluted CLS solution ( $\mathrm{pH} 10.92)$.

For 1:1000 diluted CLS solution, no colloids were mobilized at the end of our experiment $(16.5 \mathrm{PV})$, the collected effluent samples were colorless and the turbidity were very low ( 2.5-6.5 NTU). The $\mathrm{pH}$ breakthrough curve showed the pattern that $\mathrm{pH}$ decreased, then increased and then decreased. A possible reason is that the 1:1000 diluted CLS solution is fairly weak base ( $\mathrm{pH}$ 9.87) and was well buffered by the SRS sandy sediment. The column experiment ended at $16.5 \mathrm{PV}$, because it was envisioned from the trend of our data available, if any colloids would be mobilized by the 1:1000 diluted CLS solution, it might occur at $>60 \mathrm{PV}$ and the amount of colloids mobilized would be very minimal. 
Table 3. Characteristics of effluent samples collected from CLS passing through the SRS sandy sediment column

\begin{tabular}{|l|l|l|l|l|l|l|l|}
\hline $\begin{array}{l}\text { Sample } \\
\text { ID }\end{array}$ & $\begin{array}{l}\text { Pore } \\
\text { volume }\end{array}$ & $\begin{array}{l}\mathrm{pH} \text { of } \\
\text { effluents }\end{array}$ & $\begin{array}{l}\text { Conductivity of } \\
\text { effluents, } \\
\mathrm{mS} / \mathrm{cm}\end{array}$ & $\begin{array}{l}\text { Turbidity, } \\
\text { NTU }\end{array}$ & $\begin{array}{l}\text { Mean size, } \\
\mathrm{nm}^{(\mathrm{a})}\end{array}$ & $\begin{array}{l}\text { Zeta } \\
\text { potential, } \\
\mathrm{meV}^{(\mathrm{a})}\end{array}$ & $\begin{array}{l}\mathrm{pH} \text { of } \\
\text { content in } \\
\text { Zeta cell }\end{array}$ \\
\hline A7 & 1.75 & 11.51 & 0.889 & 53078.81 & $241.5 \pm 1.3$ & $-29.06 \pm 1.50$ & 7.54 \\
\hline A8 & 2.00 & 12.28 & 3.52 & 70571.25 & $251.6 \pm 3.0$ & $-27.70 \pm 1.59$ & 8.28 \\
\hline A9 & 2.25 & 12.54 & 5.73 & 50354.20 & $280.1 \pm 2.3$ & $-32.35 \pm 1.49$ & 9.51 \\
\hline A10 & 2.50 & 12.71 & 9.75 & 17148.53 & $316.3 \pm 1.6$ & $-30.29 \pm 1.20$ & 10.19 \\
\hline A11 & 2.75 & 12.78 & 12.62 & 6486.03 & $333.4 \pm 2.9$ & $-36.46 \pm 1.89$ & 10.74 \\
\hline A12 & 3.00 & 12.80 & 14.33 & 986.40 & $366.2 \pm 3.7$ & $-35.96 \pm 1.16$ & 11.65 \\
\hline
\end{tabular}

(a) Measured in DI water dilution by ZetaPlus.

Cement leachate simulant with different dilution
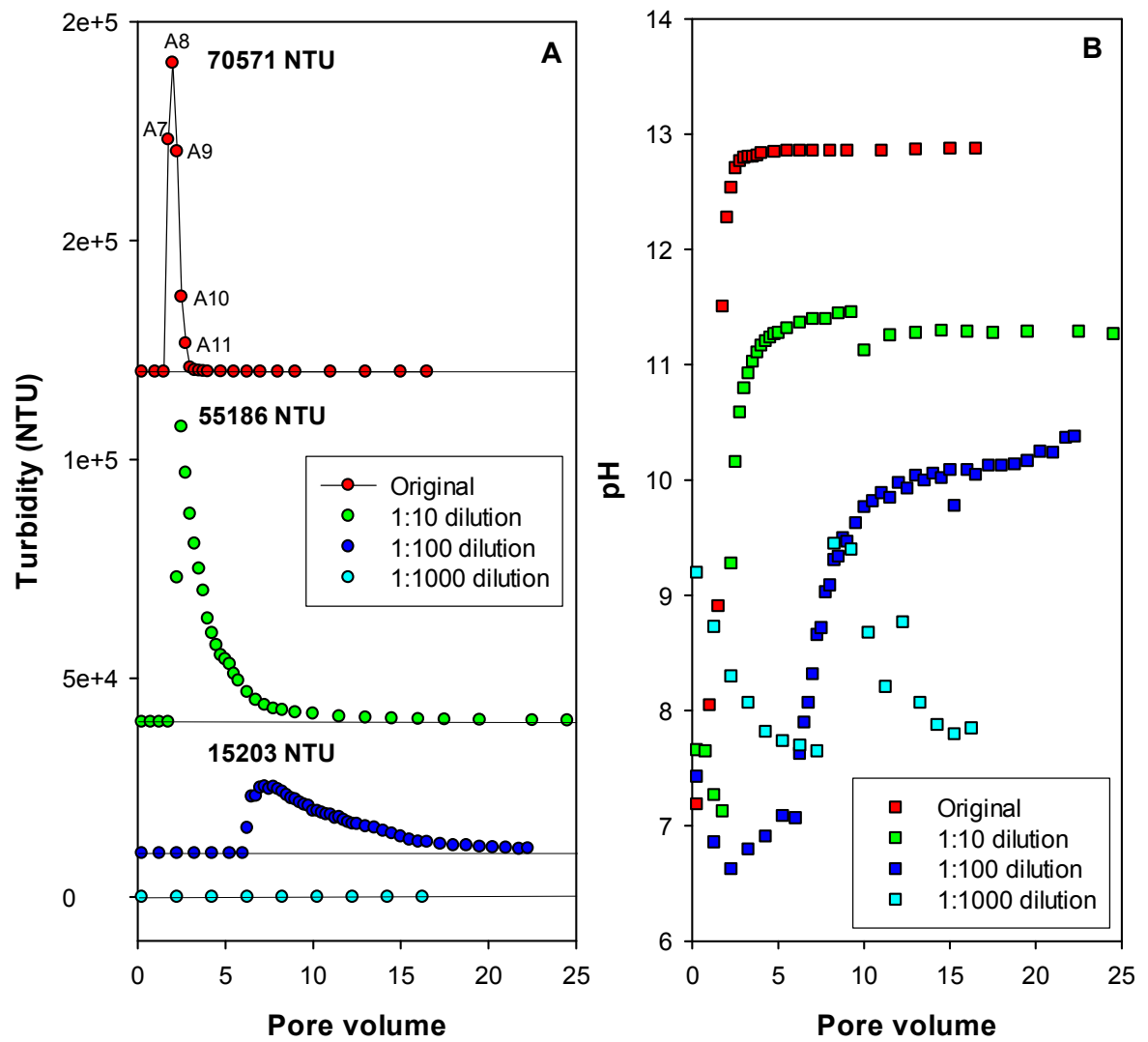

Figure 7. Turbidity (A) and pH (B) of the effluents from column experiments of

CLS (red) and its diluted solutions (green for 1:10; blue for 1:100; pink for 1:1000) vs the number of pore volumes. In Figure 7A, the solid lines represent the baseline, the turbidity of the peak and the last data point was indicated, for each column experiment. 
Figure 8 shows the relationship of the maximum turbidity of collected samples to the dilution ratio, $\mathrm{pH}$ and conductivity of the influent CLS and its diluted solutions. It is clear that with the dilution from undiluted leachate simulant, through 1:10 and 1:100 to 1:1000 diluted solutions, $\mathrm{pH}$ of the influent decreased from 12.78 to 9.87 , the conductivity of the influent decreased from $21.79 \mathrm{mS} / \mathrm{cm}$ to $0.0275 \mathrm{mS} / \mathrm{cm}$, and the turbidity of the collected samples (corresponding to the amount of colloids mobilized) decreased from 70571 NTU, through 55186 and 15203 NTU, to almost the expected zero.

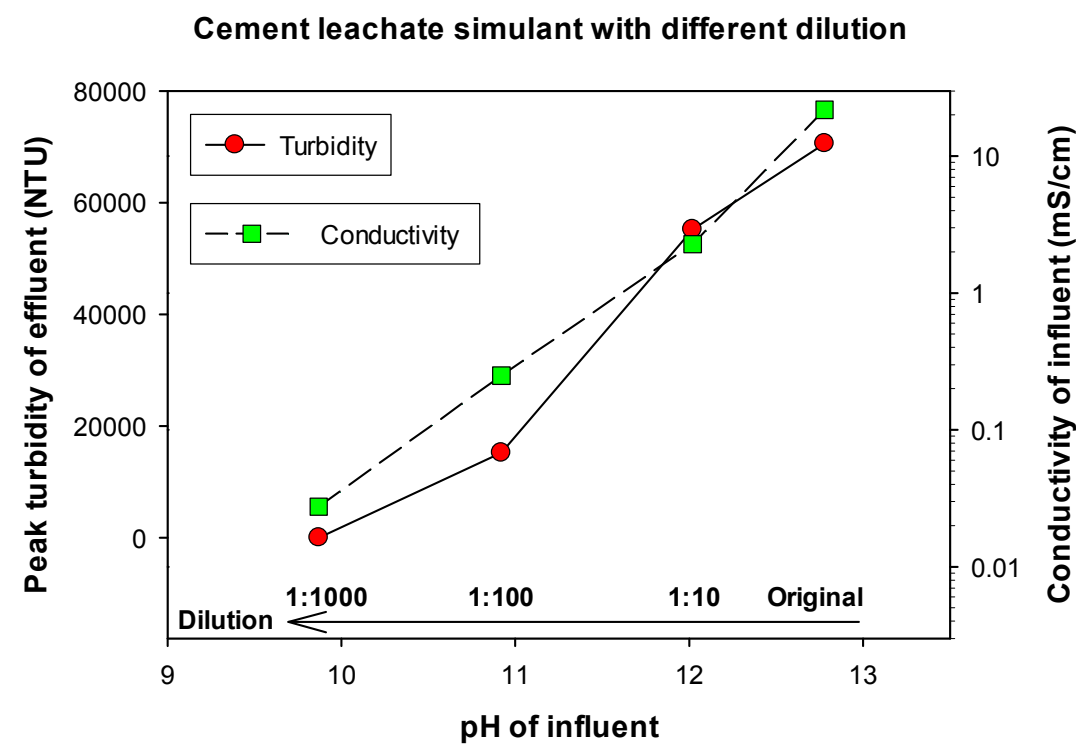

Figure 8. The maximum turbidity of the collected effluent samples against the pH and conductivity of CLS and its diluted solutions.

\subsubsection{1:10 diluted and $\mathrm{pH}$ adjusted CLS solutions}

The reason that we were interested in investigating the behavior of colloids in a diluted CLS was to simulate the colloid dispersion scenario downstream from the source where some mixing may have occurred. Furthermore, $2 \mathrm{M}$ and $0.1 \mathrm{M} \mathrm{HNO}_{3}$ solutions were used to adjust the $\mathrm{pH}$ values of the 1:10 diluted CLS solution ( $\mathrm{pH} 12.02)$ between 11.03 and 5.41 to prepare the 1:10 diluted and $\mathrm{pH}$ adjusted CLS solutions. The turbidity (A) and $\mathrm{pH}$ (B) breakthrough curves of the sandy sediment columns by the 1:10 diluted and $\mathrm{pH}$ adjusted CLS solutions are presented in Figure 9. Again, the turbidity and $\mathrm{pH}$ measurements were initiated immediately and completed within 24 hours of collecting the effluent samples. The turbidity and $\mathrm{pH}$ breakthrough curves for the 1:10 diluted CLS solution (red curves) has been described in the previous section and will not be repeated. For 1:10 diluted and $\mathrm{pH} 11.03$ CLS solutions, the colloids first emerged from the column at the 11.25 PV and $\mathrm{pH} 7.59$ and maximized at the 13.5 PV and $\mathrm{pH}$ 8.53. The maximum turbidity was 2647 NTU, and the collected samples were brownish in appearance. However, the amount of mobilized colloids reduced slowly compared to that of 1:10 diluted CLS solution, so that the plume front had a very broad tail until the termination of our column experiment at 23.25 PV. At the experiment's termination, the colloids 
continued to be mobilized, as indicated by the lightly brownish suspension samples and the turbidity of 485 NTU. The $\mathrm{pH}$ breakthrough curve also indicated the $\mathrm{pH}$ reduction prior to the plume front, and the inflection point might occur at $\sim 14.5 \mathrm{PV}$. But even after that, the $\mathrm{pH}$ kept increasing at a slower pace and the $\mathrm{pH}$ at the end of our experiment (23.25 PV) was 9.80, lower than that of the corresponding influent 1:10 diluted and $\mathrm{pH}$ 11.03 CLS solution. For 1:10 diluted and $\mathrm{pH} \leq 9.77$ CLS solutions, no colloids were mobilized at the end of our experiment (16.5 PV) and the collected samples were colorless and had low turbidity $(\sim 5 \mathrm{NTU})$. The $\mathrm{pH}$ breakthrough curve showed the pattern that $\mathrm{pH}$ decreased slightly, then increased dramatically and then increased in a slower pace. A possible reason is that the 1:10 diluted and $\mathrm{pH} \leq 9.77$ CLS solutions were fairly weak base $(\mathrm{pH}$ 9.77) or weak acid ( $\mathrm{pH} 5.41)$ and were well buffered by the SRS sandy sediment. The column experiment ended at $16.5 \mathrm{PV}$, because it was again envisioned that if any colloids would be mobilized by these 1:10 diluted and $\mathrm{pH} \leq 9.77$ CLS solution, it might occur at $>60 \mathrm{PV}$ and the amount of colloids mobilized would be very minimal, or the colloids are simply not mobilized by these influents.

1:10 diluted cement leachate simulant with then $\mathrm{pH}$ adjustemnt
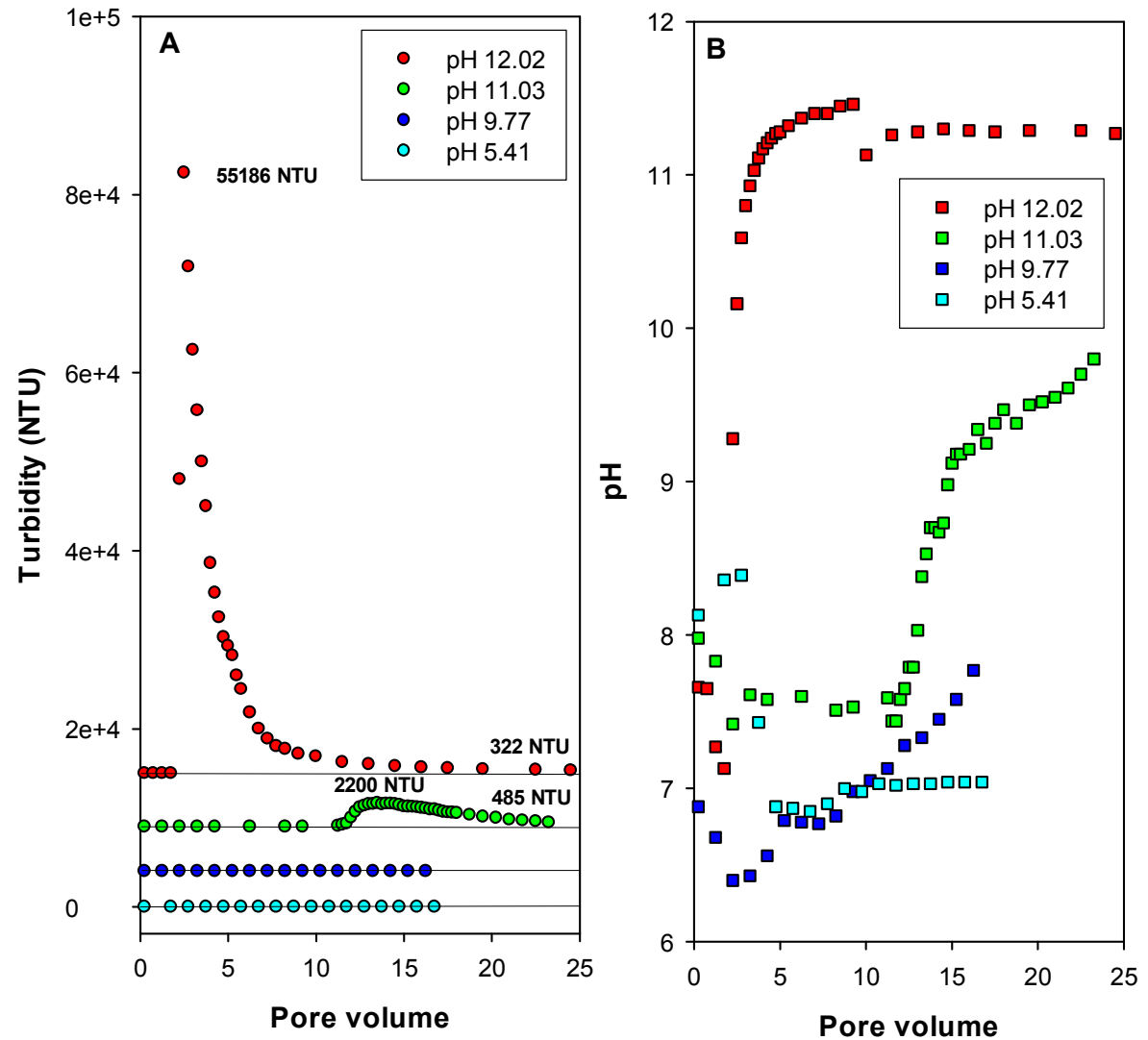

Figure 9. Turbidity (A) and pH (B) of the effluents from column experiments of 1:10 diluted and $\mathrm{pH}$ adjusted CLS solutions versus the number of pore volume. In Figure 9A, the solid lines represent the baseline, the turbidity of the peak and last data point were indicated, for each column experiment. 
Figure 10 showed the relationship of the maximum turbidity of collected effluent samples to the $\mathrm{pH}$ and conductivity of the influent 1:10 diluted and $\mathrm{pH}$ adjusted CLS solutions. It is clear that with $\mathrm{pH}$ adjustment from 12.02 through 11.03 to $\leq 9.77$, the conductivity of the influent decreased from $2.274 \mathrm{mS} / \mathrm{cm}$ to $\sim 1.191 \mathrm{mS} / \mathrm{cm}$, and the turbidity of the collected effluent samples (corresponding to the amount of colloids mobilized) decreased dramatically from 55186 NTU, through 2647 NTU to almost the expected zero.

1:10 diluted cement leachate simulant with $\mathrm{pH}$ adjustment

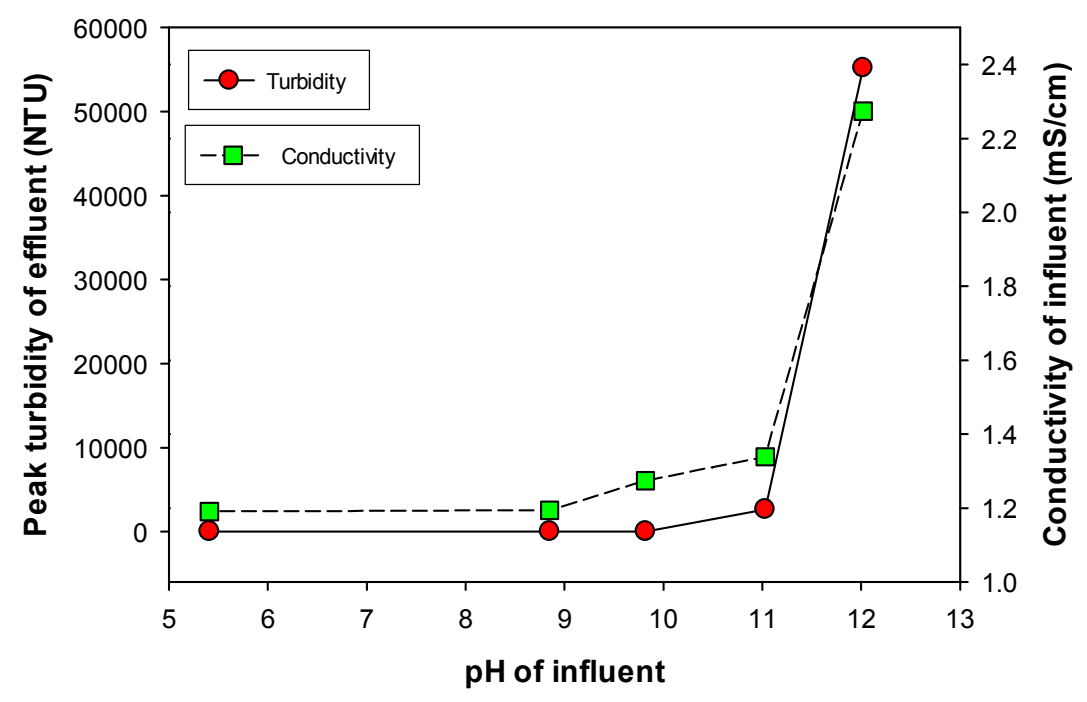

Figure 10. The maximum turbidity of the collected samples against the $\mathbf{p H}$ and conductivity of 1:10 diluted and $\mathrm{pH}$ adjusted CLS solutions.

\subsubsection{Chemical compositions of effluents}

Information on the chemical compositions of effluents can help in understanding the plume front processes, colloid mobilization mechanisms, other water-minerals interfacial processes such as ion exchange, adsorption and dissolution, and provide more perspective on how much transport and colloid mobilization are localized at the front. Major cation ( $\mathrm{Na}, \mathrm{K}, \mathrm{Ca}, \mathrm{Si}, \mathrm{Al}$ and $\mathrm{Fe}$ ) compositions of the undiluted CLS effluents of the sandy sediment column are presented in Figure 11. The cation compositions of AGW and CLS were marked as base lines in Figure 11A (Na), 11B (K) and 11C (Ca). The Si, Al and Fe in the AGW and undiluted CLS were near zero, as expected for an uncontaminated water. The labels A7 through A11 in Figure 11D refer to the effluent suspension sample identifications corresponding to pore volumes (see Figure 7A). The $\mathrm{Na}$ and $\mathrm{K}$ profiles were similar: at $\leq 2 \mathrm{PV}, \mathrm{Na}$ and $\mathrm{K}$ lay on the corresponding base lines of AGW; at $\geq \sim 3$ $\mathrm{PV}$, the $\mathrm{Na}$ and $\mathrm{K}$ were close to the corresponding base lines of undiluted CLS; the content of $\mathrm{Na}$ and $\mathrm{K}$ increased between $2 \mathrm{PV}$ and $3 \mathrm{PV}$ due to the influence from mixing of displaced AGW with the incoming undiluted CLS. In contrast, the concentrations of $\mathrm{Ca}$ in all effluents were undetected across the profile. It is important to understand where Ca was after the CLS (81.2 ppm) passed through the sandy sediment column: (1) to form calcite of $\geq 0.1 \mu \mathrm{m}$ that was mobilized with the colloids; (2) to form calcite that was 
immobilized in the sandy sediment, (3) to be immobilized in sandy sediment through surface adsorption or ion exchange mechanisms. The $\mathrm{Si}, \mathrm{Al}$ and $\mathrm{Fe}$ profiles were similar to the turbidity breakthrough curve, although Si and Al curves slightly shifted toward higher PV and had very broad tails. These results might be partially explained by the presence of nano-size kaolinite and goethite of $<0.1 \mu \mathrm{m}$ which may have passed through the filter used prior to the ICP-OES. There were other mechanisms to explain why the contents of $\mathrm{Si}$ and $\mathrm{Al}$ were higher at $\geq 3.5 \mathrm{PV}$ at which the collected effluents became colorless and had no visible sign of mobilized colloids, and why the content of Al was 24 fold as that of $\mathrm{Si}$, rather than the 1:1 ratio as seen in kaolinite. These mechanisms might include the dissolution or leaching of minerals (e.g., quartz, kaolinite, hydroxyl interlayer vermiculite, or even $\mathrm{Al}$ hydroxide) in sandy sediments.
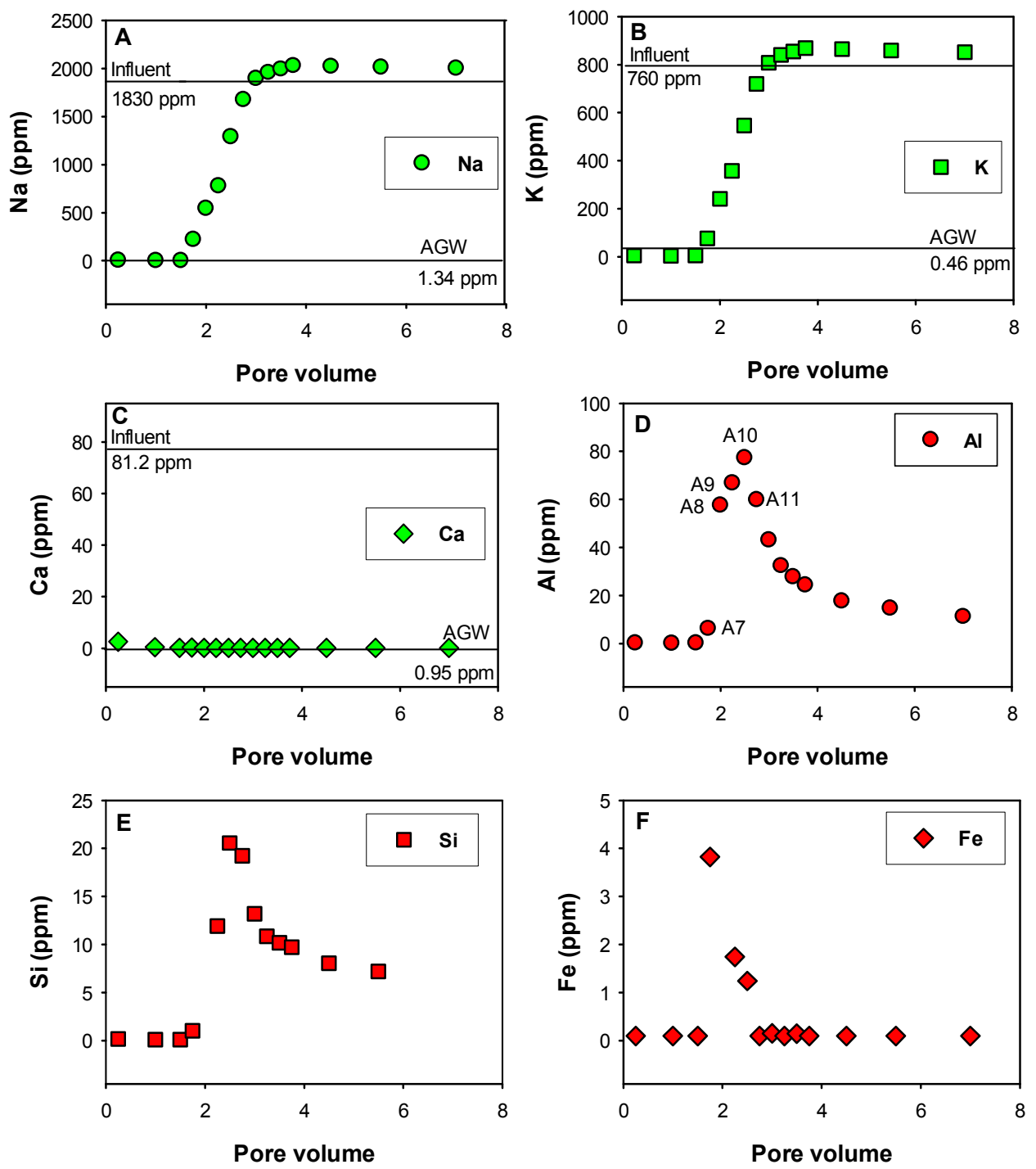

Figure 11. Breakthrough curves of major cations in the effluents of sandy sediment column by CLS (pH 12.78). 


\subsubsection{Characterization of colloids}

\subsubsection{X-ray diffraction (XRD)}

The powder XRD patterns of the air-dried colloids from the column study by undiluted CLS were presented in Figure 12. The sample labeling identifications were referred to as in Figure 7. The XRD patterns of A7, A8 and A9 were almost identical, indicating the presence of kaolinite (marked as K) and goethite (marked as G), and the kaolinite and goethite ratio was qualitatively $1: 2$, or roughly $70 \%$ goethite and $30 \%$ kaolinite. In sample A10, goethite and kaolinite were still dominant with a goethite to kaolinite ratio of $\sim 1: 2$; however, hydroxyl-interlayered vermiculite (identified as muscovite by the XRD computer library) and trona $\left(\mathrm{Na}_{3} \mathrm{H}\left(\mathrm{CO}_{3}\right)_{2} \cdot 2 \mathrm{H}_{2} \mathrm{O}\right)$ were identified. Although identification of trona was questionable, no other alternative phases were identified. The trona is most likely a precipitate from the CLS interacting with $\mathrm{CO}_{2}(g)$ in air, and unlike the other mobile colloids, did not originate from the sediment. However, no calcite was identified in the collected colloids at all, although phase diagram of this $\mathrm{Na}-\mathrm{K}-\mathrm{Ca}-\mathrm{C}-\mathrm{O}$ system indicates that calcite precipitate is dominant at $\mathrm{pH} \geq 7$ and room temperature.

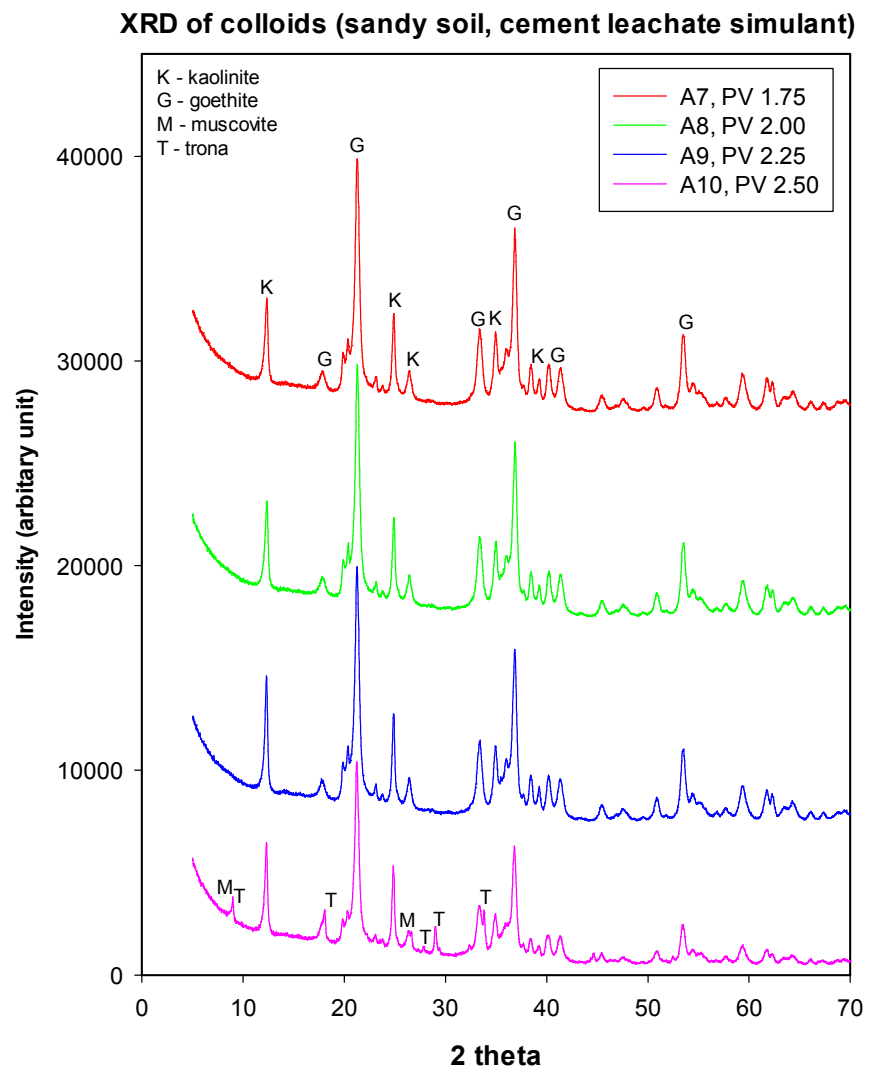

Figure 12. XRD patterns of air-dried colloids from the column study by CLS. 


\subsubsection{SEM and EDX}

The SEM images and EDX spectra of air-dried colloids collected in the SRS sandy sediment column by undiluted CLS are shown in Figure 13. The sample identification labels (A7, A8, A9, and A10) are identical to those in Figure 7. In general, The SEM images of samples A7, A8 and A9 are similar, the needle or rod-like particles are likely goethite and may be the aggregates of many nano goethite particles. The average particle sizes of the goethite are in the range of $150-350 \mathrm{~nm}$, in good agreement with PSD measurement. The larger plate-like particles are likely kaolinite. The goethite and kaolinite particles in the corresponding effluent samples were fairly stable and well dispersed; but after air-drying, the goethite particles tended to be aggregates and to stick onto larger kaolinite particles. The EDX spectra of the samples A7, A8 and A9 were also similar, the major elements present in the samples are $\mathrm{O}, \mathrm{Si}, \mathrm{Al}$ and $\mathrm{Fe}$, indicating that the major particles are Fe oxide or hydroxide like goethite $(\mathrm{FeOOH})$ and aluminum silicates like kaolinite $\left(\left(\mathrm{Al}_{2} \mathrm{Si}_{2} \mathrm{O}_{5}(\mathrm{OH})_{4}\right)\right.$, and maybe a small amount of hydroxyl-interlayered vermiculite (labeled as muscovite $\left(\mathrm{KAl}_{2}\left(\mathrm{AlSi}_{3} \mathrm{O}_{10}\right)(\mathrm{F}, \mathrm{OH})_{2}\right)$, qualitatively in good agreement the previous XRD identification of the same samples. Based on the relative intensities of $\mathrm{Si}, \mathrm{Al}$ and $\mathrm{Fe}$, it appeared that kaolinite is about equal to or slightly more than goethite in abundance, slightly in contrast to the XRD intensity. Unfortunately, we were not able to quantitatively analyze the chemical compositions of individual nano particles, because the electron beam during EDX analysis penetrates into the sample by 3 $\mu \mathrm{m}$ with a detection spot of $>2 \mu \mathrm{m}$. Carbon is likely from the carbon tape in SEM sample preparation. In addition, small amount of $\mathrm{Na}, \mathrm{P}, \mathrm{K}$ and $\mathrm{Ti}$ were detected, the corresponding mineral phases can not be firmly identified. It is simply speculated that $\mathrm{Na}$ may be from the solution precipitation, $\mathrm{K}$ may be related to hydroxyl-interlayered vermiculite $\left(\mathrm{KAl}_{2}\left(\mathrm{AlSi}_{3} \mathrm{O}_{10}\right)(\mathrm{F}, \mathrm{OH})_{2}\right)$, Ti may be in titanium oxide (e.g., like anatase as identified in XRD of $550^{\circ} \mathrm{C}$ dried SRS sandy sediment), $\mathrm{P}$ may be from the surface coating of natural organic matters on the nano particles. No calcium was detected, indicating that there was no significant amount of calcite precipitation.

In sample A10, it appeared that goethite particles tended to form larger sphere-like, rather than needle-like, aggregates. The EDX spectrum is qualitatively similar to those of the other samples, but it showed much higher $\mathrm{Na}$ and $\mathrm{K}$, indicating the presence of $\mathrm{Na}-$ and/or K-containing phases. These results are in fact coincident with the XRD pattern of this sample (A10), confirming that trona $\left(\mathrm{Na}_{3} \mathrm{H}\left(\mathrm{CO}_{3}\right)_{2} \cdot 2 \mathrm{H}_{2} \mathrm{O}\right)$ and hydroxyl-interlayered vermiculite $\left(\mathrm{KAl}_{2}\left(\mathrm{AlSi}_{3} \mathrm{O}_{10}\right)(\mathrm{F}, \mathrm{OH})_{2}\right)$ might be truly present in this sample. Again, no $\mathrm{Ca}$ was detected in this sample. 

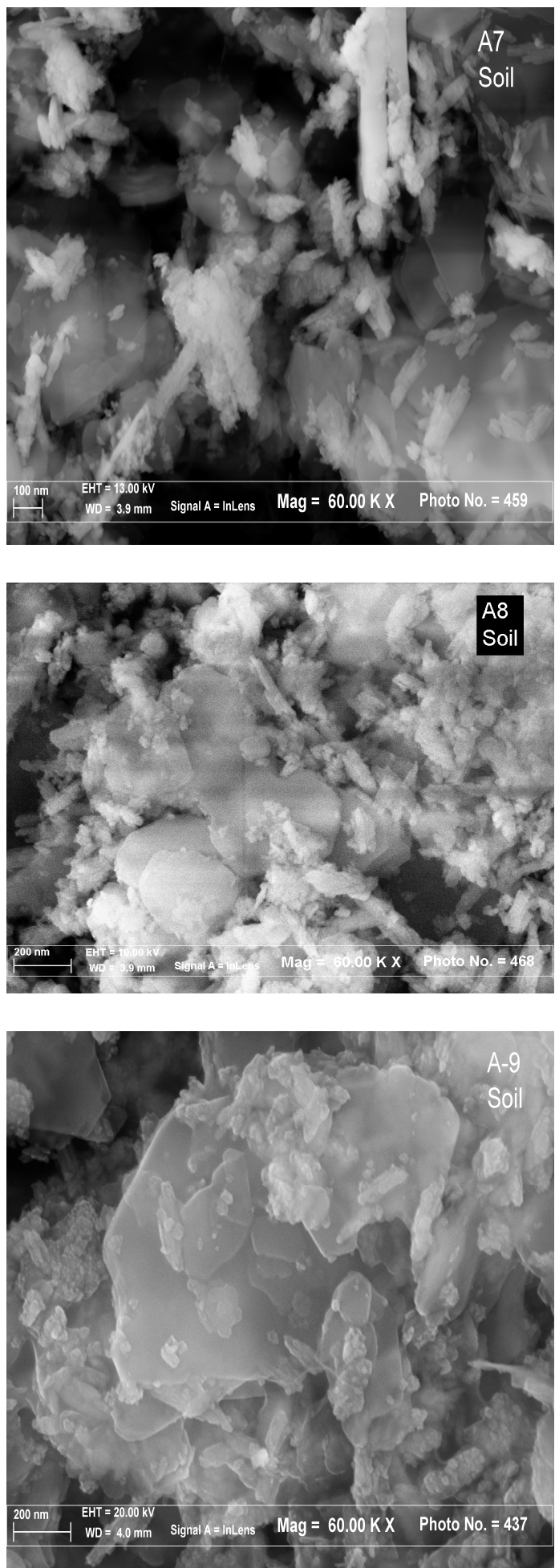
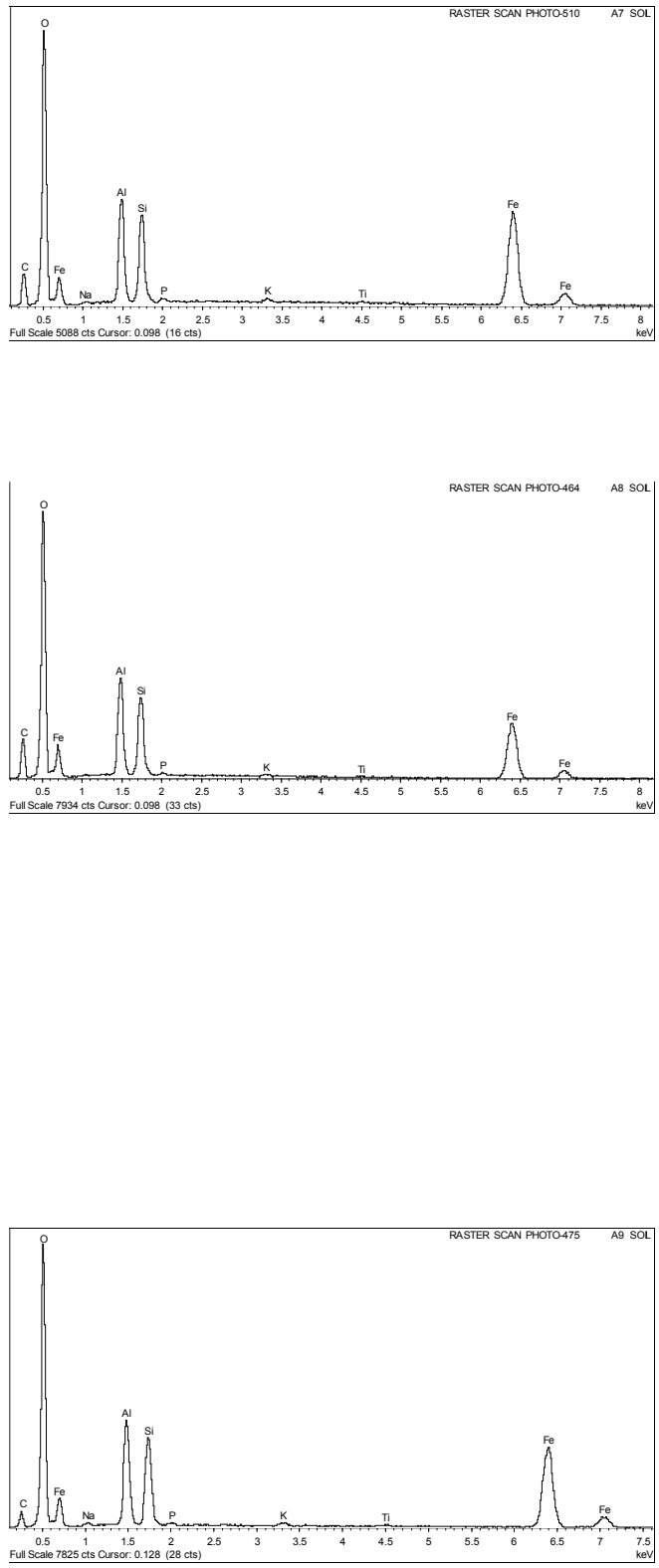

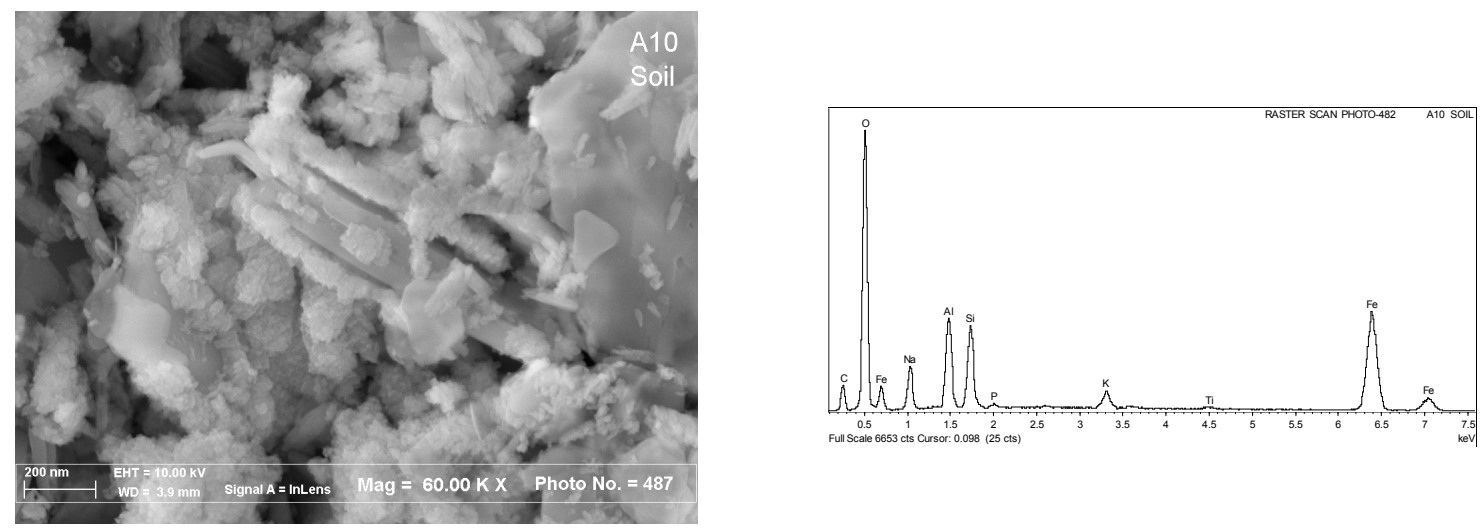

Figure 13. SEM and EDX of air-dried colloids from the SRS sandy sediment column by CLS. The sample identification labels, A7, A8, A9 and A10, are the same as shown in Figure 7.

\subsubsection{PSD and Zeta potential}

The collected colloid effluents from the column study using undiluted CLS at pH 12.78 were kept in the laboratory for $\sim 45$ days before they were sampled for PSD and Zeta potential measurement. The colloid suspension samples A7, A8 and A9 were very stable and concentrated, and just settled a little after 45 days; but the colloid suspension samples A10, A11, and A12 were not very stable and settled to the bottom of the sample container. The mean particle size and Zeta potential of the collected colloids in the effluents are shown in Figure 14 and Table 3. The PSD and Zeta measurement samples were prepared by diluting the colloid effluents with DI water in the sample cell. The $\mathrm{pH}$ of the diluted suspensions was lower than the corresponding undiluted suspensions.

Before discussing the measured Zeta potentials it is necessary to mention the zero point of charge (ZPC) of these materials. At a pH below the ZPC the Zeta potential would be expected to measure a net positive charge, whereas above the ZPC, the Zeta potential would be expected to measure a net negative charge. The ZPC for the sandy sediment has been measured to be $4.2 \pm 0.2$, for kaolinite it is reported to be about pH 4.6 (Mayer and Schick, 1981), and for goethite a pH of 7.5 (Cristiano et al., 2011).

All collected colloids have negative Zeta potentials, ranging from -27.7 to $-36.5 \mathrm{meV}$. This is expected given the extremely high $\mathrm{pH}$ of the system and the mineral assemblage (kaolinite, goethite, hydroxyl-interlayered vermiculite, and trace amounts of trona and anatase). The Zeta potential remained largely the same or may have slightly decreased as the pore volumes increased. The mean particle sizes of the mobilized colloids increased from $241.8 \mathrm{~nm}$ to $366.6 \mathrm{~nm}$ across the PV range from 1.75 to 3 , indicating that the smaller size colloids tended to be mobilized first. Our observation appeared to be fairly well explained by electrostatic and filtration theory in saturated porous media (Elimelech and O'Melia, 1990; Elimelech 1994; Huber et al., 2000; Tufenkij and Elimelech 2004, Zhuang et al., 2005). Zhuang et al. (2005) studied the effects of particle size and surface property on the retention and transport of amphiphilic colloids in saturated and 
unsaturated flow conditions. They found that as particle size decreased within the range of $20 \mathrm{~nm}$ to $420 \mathrm{~nm}$, colloid attachment efficiency first decreased to reach a minimum value at the size range of $100 \mathrm{~nm}$ to $350 \mathrm{~nm}$, and then increased, which indicated that the particles at the range of $100-350 \mathrm{~nm}$ are more mobile than other particles. In a previous study reported, Huber et al. (2000) conducted short-pulse experiments using fluorescence labeled latex colloids and studied the removal efficiency of colloids in natural porous media, in relation to the ion strength of the solution and the counterion valence. They found that the removal efficiency of a filter bed is influenced by the type of electrolyte, its concentration, and the porous media. An attachment parameter, $\alpha$, describes the dependence of the removal efficiency on the electrolyte concentration qualitatively. Normalization of $\alpha$ by the valence of the dominant counterion describes the removal efficiency of the kind of electrolyte. Their results also indicated that the removal efficiency (\%) of colloid particles decreased from $100 \mathrm{~nm}$ to $1000 \mathrm{~nm}$, and then increased from $1000 \mathrm{~nm}$ to $10000 \mathrm{~nm}$, which meant that the $100 \mathrm{~nm}$ to $1000 \mathrm{~nm}$ colloids are more mobiles and the mobility decreased with the particle size in the size range of 100 to 1000 $\mathrm{nm}$. Our observations from the SRS sandy sediment column by undiluted CLS indicated that the particle sizes of mobilized colloids are 240-370 nm, and the smaller colloids tended to be mobilized first, which is in good agreement with previous studies on the transport of colloids in porous media.

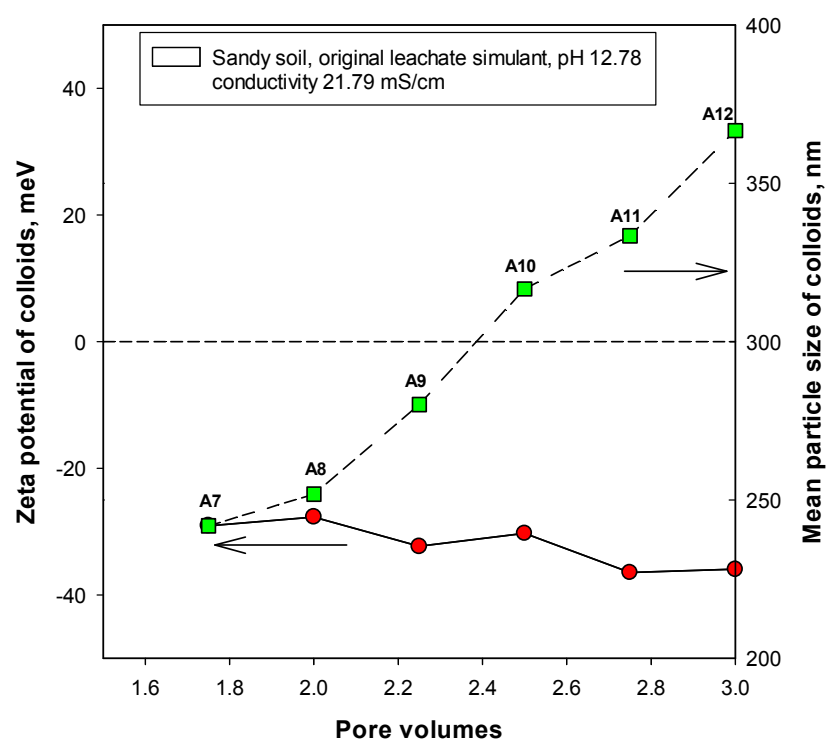

Figure 14. Mean particle size (green squares) and Zeta potential (red circles) of collected colloid suspensions. A7 to A12 are the sample labels as in Figure 1.

For the selected samples from column studies with 1:10 diluted CLS solutions at $\mathrm{pH}$ 12.02, $\mathrm{pH} 11.03$, and with 1:100 diluted CLS solution at $\mathrm{pH} 10.92$, the PSD and Zeta potential of colloids in the direct effluents were measured using ZetaPlus at SRNL. The sample preparation for these PSD and Zeta measurements were described as follows: the effluents with mobilized colloids were kept in the laboratory for $\sim 3$ months, the top clear liquid from each effluent was collected by pipetting and the remaining effluent with particles were shaken and re-dispersed, a certain amount of colloids was transferred to the 
corresponding clear effluent solution to make the suspension of right colloid concentration for PSD and Zeta measurement. However, for samples SS12.02-10-A10, A12 and A16, the colloids in the effluents were dispersed so well that they were not completely settled down after $\sim 3$ months. As a result, DI water was used as a diluent in preparation of diluted suspension samples for PSD and Zeta measurement, although the dilution would reduce the $\mathrm{pH}$ and shift the ZPC toward the positive direction. As shown in Table 4, the results indicated that the mobilized colloids in the direct effluents were all negatively charged. The mean particle sizes of the mobilized colloids in the direct effluents were $<1000 \mathrm{~nm}$, mostly in the range of 200-470 nm, in good agreement with the undiluted CLS study. The two samples (SS10.92-100-25 and SS10.92-100-26) had a mean particle size of $800-1000 \mathrm{~nm}$, probably due to slight agglomeration during the storage.

Table 4. Mean particle size and Zeta potential of colloids in the direct effluents of CLS column experiments

\begin{tabular}{|c|c|c|c|c|c|c|}
\hline Sample ID & $\begin{array}{l}\text { No. of } \\
\text { PV }\end{array}$ & $\begin{array}{l}\mathrm{pH} \text { of } \\
\text { effluent }\end{array}$ & $\begin{array}{l}\mathrm{C} \text { of } \\
\text { effluent, } \\
\mathrm{mS} / \mathrm{cm}\end{array}$ & Diluent & $\begin{array}{l}\text { Mean size, } \\
\text { nm }\end{array}$ & $\begin{array}{l}\text { Zeta } \\
\text { potential, } \\
\mathrm{mV}\end{array}$ \\
\hline \multicolumn{2}{|l|}{ 1:10 diluted CLS ${ }^{(b)}$} & 12.02 & 2.274 & & & \\
\hline SS12.02-10-A9 & 2.25 & 9.28 & 0.124 & Effluent & $334.8 \pm 2.7$ & $-39.1 \pm 2.89$ \\
\hline SS12.02-10-A10 & 2.50 & 10.16 & 0.344 & $\mathrm{DI}^{(\mathrm{a})}$ & $236.8 \pm 2.0$ & $-25.24 \pm 1.23$ \\
\hline SS12.02-10-A12 & 3.00 & 10.80 & 0.332 & $\mathrm{DI}^{(\mathrm{a})}$ & $251.4 \pm 2.8$ & $-21.11 \pm 0.83$ \\
\hline SS12.02-10-A16 & 4.00 & 11.17 & 0.405 & $\mathrm{DI}^{(\mathrm{a})}$ & $269.9 \pm 3.0$ & $-28.79 \pm 1.02$ \\
\hline SS12.02-10-A24 & 6.00 & 11.35 & 1.188 & Effluent & $254.8 \pm 1.9$ & $-43.79 \pm 1.29$ \\
\hline SS12.02-10-A40 & 10.00 & 11.13 & 1.026 & Effluent & $204.2 \pm 1.5$ & $-43.44 \pm 1.88$ \\
\hline SS12.02-10-A48 & 12.00 & 11.26 & 1.078 & Effluent & $203.7 \pm 2.5$ & $-42.49 \pm 2.19$ \\
\hline SS12.02-10-A52 & 13.00 & 11.28 & 1.168 & Effluent & $387.3 \pm 3.9$ & $-48.85 \pm 4.20$ \\
\hline \multicolumn{2}{|l|}{ 1:10 diluted CLS ${ }^{(b)}$} & 11.03 & 1.339 & & & \\
\hline SS11.03-10-A48 & 12.00 & 7.58 & 0.970 & Effluent & & \\
\hline SS11.03-10-A52 & 13.00 & 8.03 & 0.967 & Effluent & $430.1 \pm 3.7$ & $-36.66 \pm 3.18$ \\
\hline SS11.03-10-A56 & 14.00 & 8.70 & 0.989 & Effluent & $383.3 \pm 5.0$ & $-39.01 \pm 2.53$ \\
\hline SS11.03-10-A64 & 16.00 & 9.21 & 0.982 & Effluent & $378.5 \pm 2.1$ & $-46.49 \pm 3.01$ \\
\hline SS11.03-10-A74 & 18.50 & 9.47 & 0.982 & Effluent & $374.9 \pm 5.2$ & $-36.59 \pm 2.73$ \\
\hline SS11.03-10-A90 & 22.50 & 9.70 & 0.992 & Effluent & $469.1 \pm 3.5$ & $-38.78 \pm 1.80$ \\
\hline \multicolumn{2}{|l|}{ 1:100 diluted CLS ${ }^{(b)}$} & 10.92 & 0.249 & & & \\
\hline SS10.92-100-25 & 6.25 & 7.63 & 0.060 & Effluent & $895.8 \pm 59.2$ & $-22.79 \pm 0.93$ \\
\hline SS10.92-100-26 & 6.50 & 7.90 & 0.055 & Effluent & $992.3 \pm 65.1$ & $-24.95 \pm 0.46$ \\
\hline SS10.92-100-30 & 7.25 & 8.66 & 0.061 & Effluent & $416.9 \pm 4.1$ & $-26.19 \pm 1.21$ \\
\hline SS10.92-100-36 & 9.00 & 9.47 & 0.069 & Effluent & $311.1 \pm 5.6$ & $-30.66 \pm 1.36$ \\
\hline SS10.92-100-42 & 10.50 & 9.82 & 0.077 & Effluent & $314.8 \pm 5.2$ & $-33.53 \pm 1.26$ \\
\hline SS10.92-100-68 & 17.00 & 10.13 & 0.087 & Effluent & $265.3 \pm 2.5$ & $-36.39 \pm 1.80$ \\
\hline
\end{tabular}

(a) PSD and Zeta potentials of these samples were measured in DI diluent due to good dispersion after $\sim 3$ months. The pHs of the DI suspensions were 7.96 (A10), 8.41 (A12), 8.29 (A16).

(b) $\mathrm{pH}$ and conductivity are those of influent leachate solutions. 
Zeta potentials of ground SRS sandy sediment, model minerals - kaolinite and goethite were measured in undiluted CLS and its 1:10, 1:100 and 1:1000 diluted solutions and in 1:10 diluted CLS solution ( $\mathrm{pH}$ 12.02) and its $\mathrm{pH}$ adjusted solutions $(\mathrm{pH} 11.03,9.87$ and 8.77). Most of the Zeta potential data were measured using ZetaPlus at SRNL; however, the Zeta potentials of SRS sandy sediment, kaolinite and goethite in undiluted CLS were measured using ZetaPals at Brookhaven Instrument Corporation, because its conductance was too high to be measured by ZetaPlus. The measured Zeta potentials of sandy sediment (red circles), kaolinite (green squares) and goethite (pink diamonds) in the corresponding diluents were present in Figure 15, where the Zeta potentials of sandy sediment, kaolinite and goethite in AGW were included in Figure 15A for comparison. It was noted that the Zeta potentials of sandy sediment, kaolinite and goethite in the undiluted CLS by ZetaPals were less negative than the data of the corresponding particles in the 1:10 diluted CLS solution measured by ZetaPlus. The discrepancies may be true, but also these might be caused simply by two different instruments.
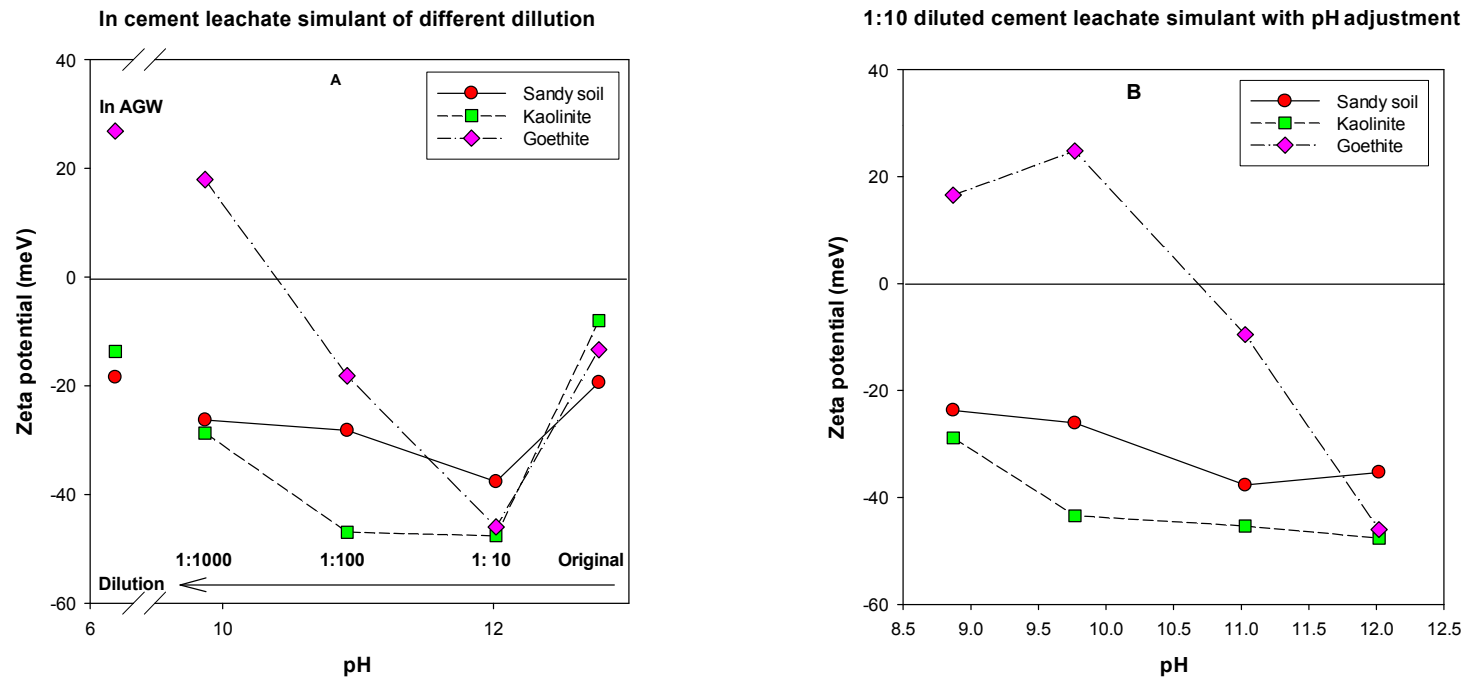

Figure 15. Zeta potentials of SRS sandy sediment (red circles), kaolinite (green squares) and goethite (pink diamonds) in (A) CLS and its diluted solutions and (B) 1:10 diluted and pH adjusted CLS solutions. Zeta potentials of the minerals in undiluted CLS were measured using ZetaPals at Brookhaven Instruments, Inc. All other were measured on ZetaPlus at SRNL.

As shown in Figure 15A, for CLS and its diluted solutions, goethite had positive surface charge in AGW and 1:1000 diluted CLS solution, and SRS sandy sediment (quartz with very small amount of goethite and kaolinite) and kaolinite have negative surface charge in AGW and 1:1000 diluted CLS solution, which are expected for low electrolyte solutions. However, in undiluted, 1:10 and 1:100 diluted CLS solutions, sandy sediment, kaolinite and goethite all have negative surface charges. From 1:100 to 1:10 diluted solution, the surface charges of these minerals tended to become even more negative, being repulsive toward each other. 
As shown in Figure 15B, for the 1:10 diluted and $\mathrm{pH}$ adjusted CLS solutions, sandy sediment and kaolinite remained negative with the $\mathrm{pH}$ titration from 12.03 to 8.77 in the 1:10 diluted CLS solutions. However, goethite had a very negative surface charge at 1:10 diluted CLS solution ( $\mathrm{pH}$ 12.02); it had a less negative surface charge at $\mathrm{pH} 11.03$. With the $\mathrm{pH}$ of the 1:10 diluted CLS solution further reduced, goethite had a positive surface charge $\mathrm{pH} 9.87$ and 8.85 .

The Zeta potential data can well explain the turbidity breakthrough curves of the SRS sandy sediment in CLS and its diluted solutions or 1:10 diluted and $\mathrm{pH}$ adjusted CLS solutions. Furthermore, although the mobilization processes of colloids in the column studies are very complex, the available data indicated that the mobilization mechanism of goethite and kaolinite colloids from the SRS sandy sediment is primarily due to the surface electrostatic behavior of particles in the influent leachate solutions. As seen in Figure 16, with the influent of AGW (pH 7.15 and conductivity $24.0 \mu \mathrm{S} / \mathrm{cm}$ ), kaolinite and sandy sediment grain (quartz) in the column have negative surface charge, but goethite has positive surface charge. Nano size goethite and kaolinite are cemented together and coat the surface sand grains due to the strong electrostatic attraction. As a result, minimum amount of kaolinite and goethite colloids were mobilized (Figure 16A). However, with the influent of CLS ( $\mathrm{pH} 12.78$ and conductivity $21.79 \mathrm{mS} / \mathrm{cm}$ ), kaolinite and sand grains remained negative in surface charges, and goethite's surface charge became negative. Therefore, the kaolinite and goethite colloids are dispersed and released from sand grain surface due to the electrostatic repulsion, and these colloids are mobilized to form a plume front of high turbidity in the breakthrough curve (Figure 16A). This mechanism also explains why the kaolinite and goethite colloids are mobilized from the SRS sandy sediments in the 1:10 and 1:100 diluted CLS solution, and 1:10 diluted and $\mathrm{pH}$ adjusted to $11.03 \mathrm{CLS}$ solutions, because goethite and kaolinite are all have negative surface charge in these solutions. In contrast, in 1:1000 diluted CLS solution and 1:10 diluted but $\mathrm{pH}$ adjusted to $\leq 9.77$ CLS solution, very minimum amount of goethite and kaolinite colloids were mobilized and released, because like in AGW, goethite has positive surface charge, but kaolinite and sand grains have negative surface charged, so that kaolinite and goethite were cemented together and coat the sand grain surfaces. Although our observations appeared to be in contrast to the conventional concept that to lower ion strength usually enhances colloid particle release, in the systems with $\mathrm{pH}$ dependent surface charge like goethite, kaolinite and sand grain, colloid release is more influenced by $\mathrm{pH}$ rather than by ion strength. 


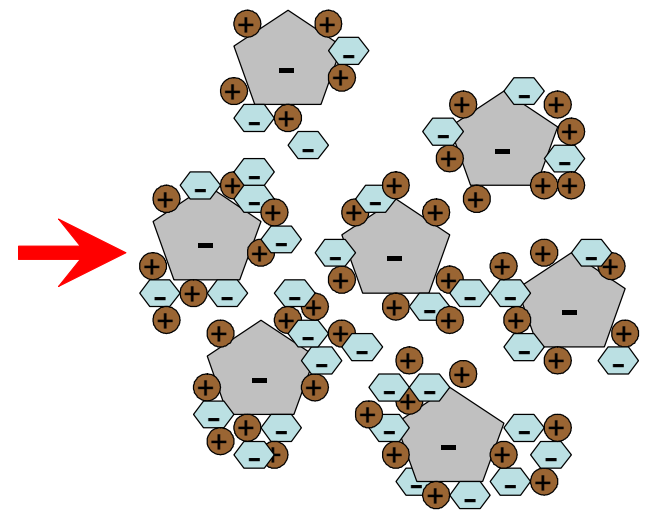

Soil grain

\section{A. Artificial groundwater}

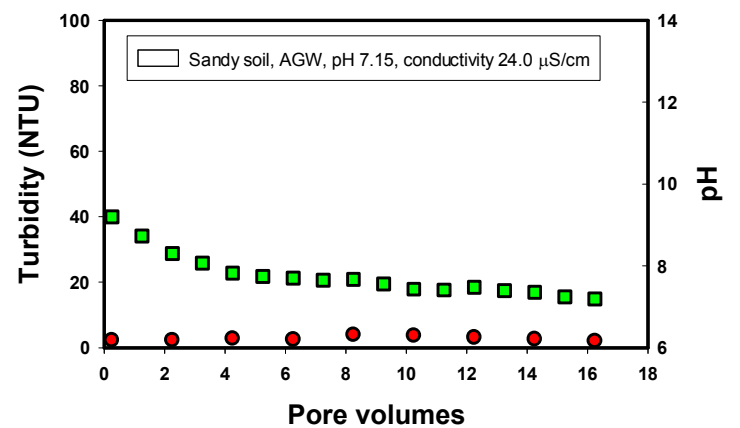

C. Turbidity vs PV of AGW

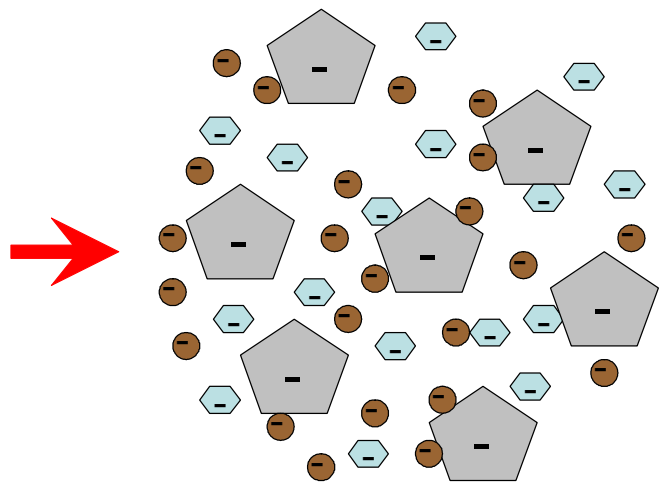

Kaolinite

Goethite

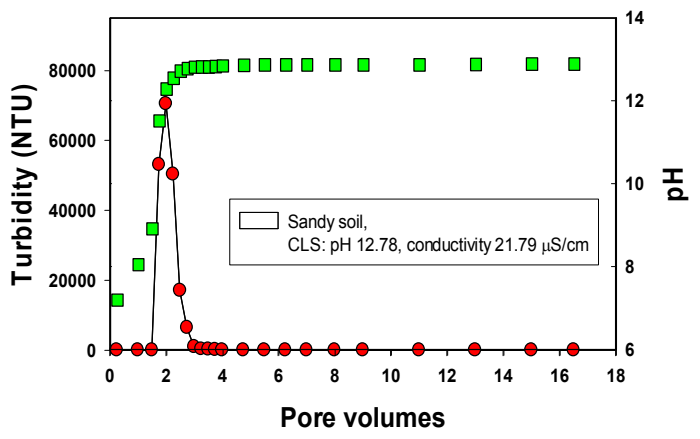

D. Turbidity vs PV of CLS

Figure 16. Schematic diagram showing mobilization mechanism of nano goethite and kaolinite in SRS sandy sediment column by cement leachate stimulant (B), in comparison with artificial groundwater (A). Experimental turbidity vs. pore volume of AGW (C) and cement leachate stimulant (CLS) (D). (Note difference between $y$-axis scales in (C) and (D)).

\subsection{Column Experiment - GCL}

\subsubsection{Column experiment}

The turbidity (red circles) and $\mathrm{pH}$ (green squares) breakthrough curves of the sandy sediment columns by undiluted GCL (A) and its 1:10 diluted solution (B) are presented in Figure 17. The turbidity, $\mathrm{pH}$ and conductivity measurements were performed as soon as effluent samples were collected (within 24 hours). The relevant data for the GCL were summarized in Table 5. Sample identifications 1-9 and 1-10 in the turbidity breakthrough curve (Figure 17A) correspond to PV 2.25 and 2.50, respectively, and will be referred to in the following sections on chemical compositions of effluents and the characterization of colloids. The colloids in effluents emerged and maximized from the column at $2.25 \mathrm{PV}$ 
of the genuine leachate injection. This was expected because the column was flushed by AGW for 25 PV and supposed to be saturated. Additionally, the dead-volume accounting for tubing connection among the stock solution tank, the column and the fraction collector was about $17.6 \mathrm{~mL}$, which was almost one PV of the column $(20.6 \mathrm{~mL})$. The plume front location emerged at 2.25 PV and the maximum turbidity was $\sim 37473.5 \mathrm{NTU}$ at $2.25 \mathrm{PV}$ and $\mathrm{pH}$ 10.08. The collected suspension effluent was very brownish in appearance. After that, the mobilization of colloids reduced sharply, a very minimal amount of colloids were mobilized after $2.5 \mathrm{PV}$, as indicated by the appearance of collected samples and the very low turbidity. $\mathrm{pH}$ reduction prior to the plume front was observed, $\mathrm{pH}$ of the effluents then increased toward the $\mathrm{pH}$ (12.3) of the influent GCL, the inflection point occurred at $\sim 3.5 \mathrm{PV}$.

As shown in Figure 17B for 1:10 diluted GCL solution, the colloids first emerged from the column at the 3.75 PV and $\mathrm{pH} 8.0$ and maximized at the 4.25 PV and $\mathrm{pH} 8.69$. The maximum turbidity was $8217.38 \mathrm{NTU}$, and the collected samples were brownish in appearance. However, the mobilization of colloids reduced slower compared to that of the undiluted GCL so that the plume front was shown to be a broader peak with a tail of lower turbidity. In fact, the colloids continued being mobilized until $25 \mathrm{PV}$ in our experiment, as indicated by the lightly brownish suspension samples and the turbidity of 20.65 NTU. The $\mathrm{pH}$ breakthrough curve indicated the $\mathrm{pH}$ reduction prior to the plume front, the inflection point was insignificant, and $\mathrm{pH}$ steadily increased to 11.18 the end of the experiment (24.25 PV), slightly lower than that of the 1:10 diluted GCL solution (pH 11.74).

Comparing the turbidity breakthrough curves for undiluted GCL and its 1:10 diluted solution shows that the former had a sharper plume, that broke through earlier, and it had a much higher maximum turbidity than the latter. The turbidity breakthrough peak from the 1:10 diluted solution had a longer tail and contained much less mobile colloids than the full strength GCL influent solution suspension.

\section{Table 5. Characteristics of collected samples in SRS sandy sediment column by undiluted GCL}

\begin{tabular}{|l|c|c|c|c|c|c|}
\hline $\begin{array}{l}\text { Sample } \\
\mathrm{ID}^{\text {(a) }}\end{array}$ & $\begin{array}{l}\text { Pore } \\
\text { volume }\end{array}$ & $\begin{array}{l}\mathrm{pH} \text { of } \\
\text { effluents }\end{array}$ & $\begin{array}{l}\text { Conductivity of } \\
\text { effluents, } \mathrm{mS} / \mathrm{cm}\end{array}$ & $\begin{array}{l}\text { Turbidity, } \\
\text { NTU }\end{array}$ & $\begin{array}{l}\text { Mean size, } \\
\mathrm{nm}\end{array}$ & $\begin{array}{l}\text { Zeta potential, } \\
\mathrm{mV}(\mathrm{b})\end{array}$ \\
\hline $1-7$ & 1.75 & 7.25 & 0.217 & 3.843 & & -23.28 \\
\hline $1-9$ & 2.25 & 10.08 & 0.393 & 37473.5 & 310.5 & -25.25 \\
\hline $1-10$ & 2.50 & 10.55 & 0.609 & 5709.91 & 756.6 & \\
\hline $1-11$ & 2.75 & 11.69 & 1.749 & 164.879 & & \\
\hline $1-12$ & 3.00 & 12.15 & 3.64 & 38.408 & & \\
\hline $1-14$ & 3.50 & 12.33 & 5.17 & 17.453 & \\
\hline
\end{tabular}



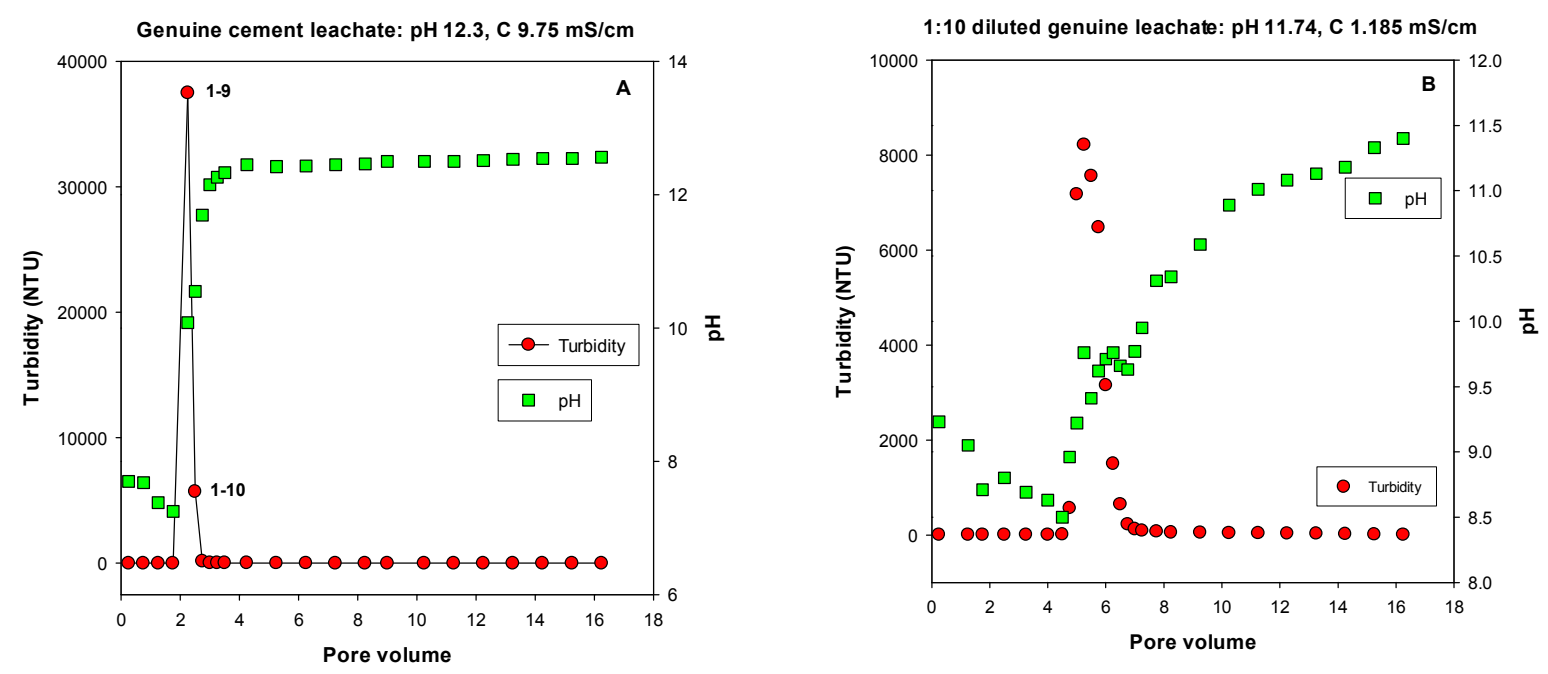

Figure 17. Turbidity (red circles) and pH (green squares) breakthrough curves in the SRS sandy sediment columns by undiluted GCL (A) and 1:10 diluted GCL solution (B).

\subsubsection{Chemical compositions of effluents}

Major cation ( $\mathrm{Na}, \mathrm{K}, \mathrm{Ca}, \mathrm{Si}, \mathrm{Al}$ and $\mathrm{Fe})$ compositions of the effluents $(<0.1-\mu \mathrm{m}$ filtered and preserved in $0.2 \mathrm{~N}$ nitric acid) from the sandy sediment column by undiluted GCL $(\mathrm{pH} 12.30)$ are presented in Figure 18. The cation compositions of AGW and the undiluted GCL were marked as base lines. The labels 1-9 and 1-10 were the sample identifications (see Figure 17A). The $\mathrm{Na}$ and $\mathrm{K}$ profiles were similar: at $\leq 1.75 \mathrm{PV}, \mathrm{Na}$ and $\mathrm{K}$ lay on the corresponding base lines of $\mathrm{AGW}$; at $\geq \sim 3 \mathrm{PV}$, the $\mathrm{Na}$ and $\mathrm{K}$ were close to the corresponding base lines of GCL. The content of $\mathrm{Na}$ and $\mathrm{K}$ increased between 1.75 $\mathrm{PV}$ and $3 \mathrm{PV}$ due to the influence from mixing of displaced AGW with the incoming GCL. In contrast, the contents of $\mathrm{Ca}$ in the collected effluents at $\mathrm{PV} \leq 2.50$ were on the baseline of AGW, then steadily increased up to $3.5 \mathrm{PV}$. However, the content of $\mathrm{Ca}$ in the effluent at 3.5 PV (402.8 ppm) was still far below the Ca content $(765 \mathrm{ppm})$ of the influent GCL, which meant that a portion of $\mathrm{Ca}$ was removed by the column sandy sediment or left as mobile colloids. It is important to track the fate of $\mathrm{Ca}$ as the GCL passed through the sandy sediment column. It is possible that it was associated with: (1) $\geq$ $0.1 \mu \mathrm{m}$ calcite fraction that was mobilized with the colloids; (2) a calcite fraction that was immobilized in the sandy sediment, (3) a surface adsorption or ion exchange sorbed fraction on the sandy sediment. The $\mathrm{Si}, \mathrm{Al}$ and Fe profiles were similar to the turbidity breakthrough curves, although Si and Al curves slightly shifted toward higher PV and had very broad tails. These results might be partially explained by the presence of nanosize kaolinite and goethite of $<0.1 \mu \mathrm{m}$ which were passed through the filter. There were other mechanisms (e.g., dissolution of Al oxide or hydroxide) to explain why the contents of Al was 15 fold higher than $\mathrm{Si}$ at 2.5 and $2.75 \mathrm{PV}$, rather than the 1:1 ratio as seen in kaolinite. The general conclusions from the groundwater chemistry of the GCL and the CLS column studies were essentially identical, providing added validity to these results. 

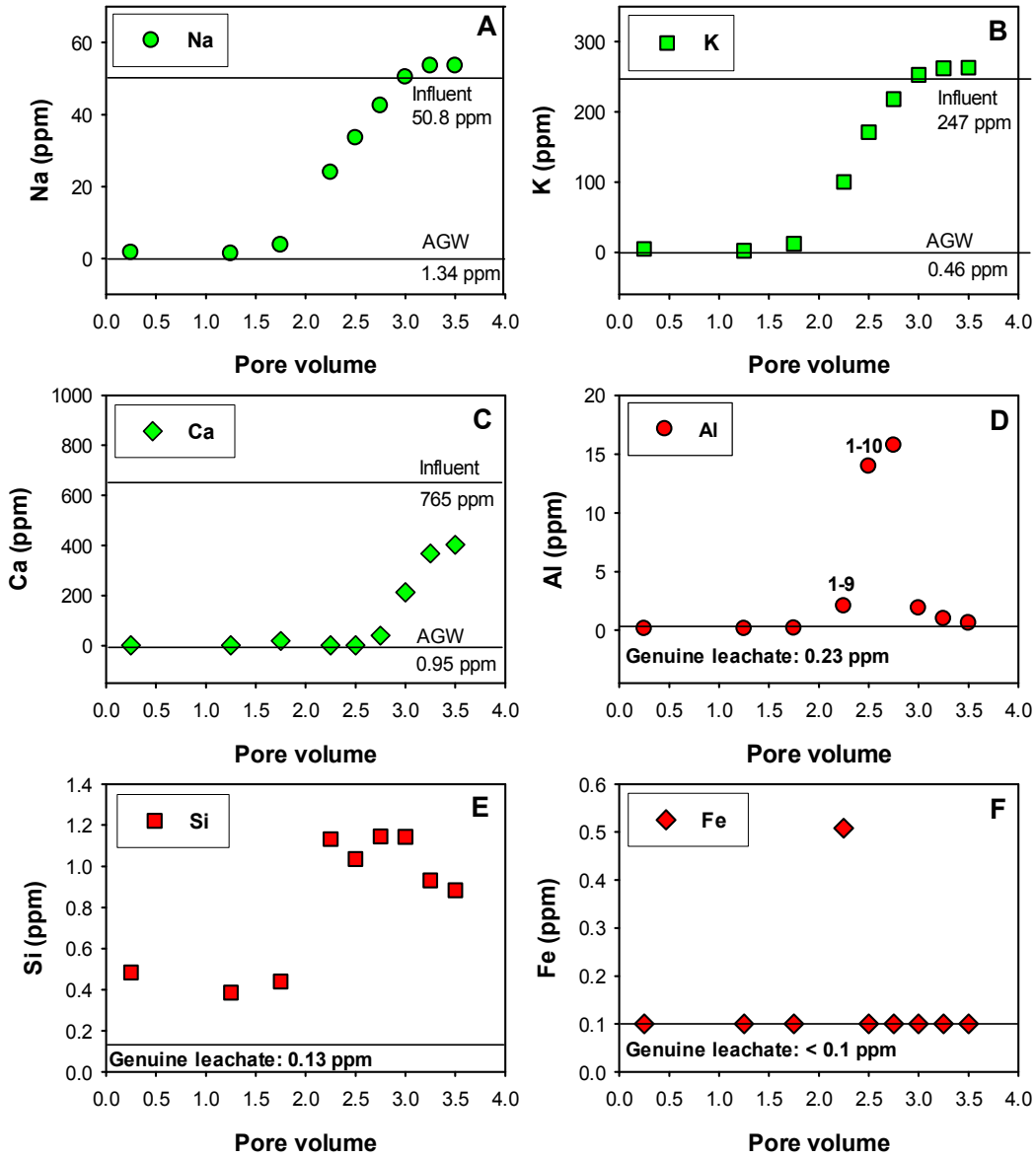

Figure 18. Breakthrough curves of major cations in the effluents of sandy sediment column by undiluted GCL (pH 12.30).

\subsubsection{Characterization of colloids}

\subsubsection{XRD}

The powder XRD patterns of the air-dried colloids from the column study by undiluted GCL were presented in Figure 19. Only two collected effluents had significant amount of colloids, the sample labeling identification were 1-9 and 1-10 (see Figure 17A). The effluent suspension of sample 1-9 was well dispersed and fairly stable even after $\sim 45$ days. The XRD pattern indicated the presence of kaolinite (marked as K) and goethite (marked as G), and the kaolinite and goethite ratio was qualitatively 1:2, or roughly $70 \%$ goethite and 30\% kaolinite. The effluent suspension of sample 1-10 was not stable and settled fast, only a very small amount of colloids were collected for sample A10. Its XRD pattern indicated that goethite and kaolinite were still dominant, but kaolinite is more abundant than goethite. No calcite or any other mineral phase was firmly identified in the collected colloid, although phase diagram of this $\mathrm{Na}-\mathrm{K}-\mathrm{Ca}-\mathrm{C}-\mathrm{O}$ system indicates that calcite precipitate is dominant at $\mathrm{pH} \geq 7$ and room temperature. 


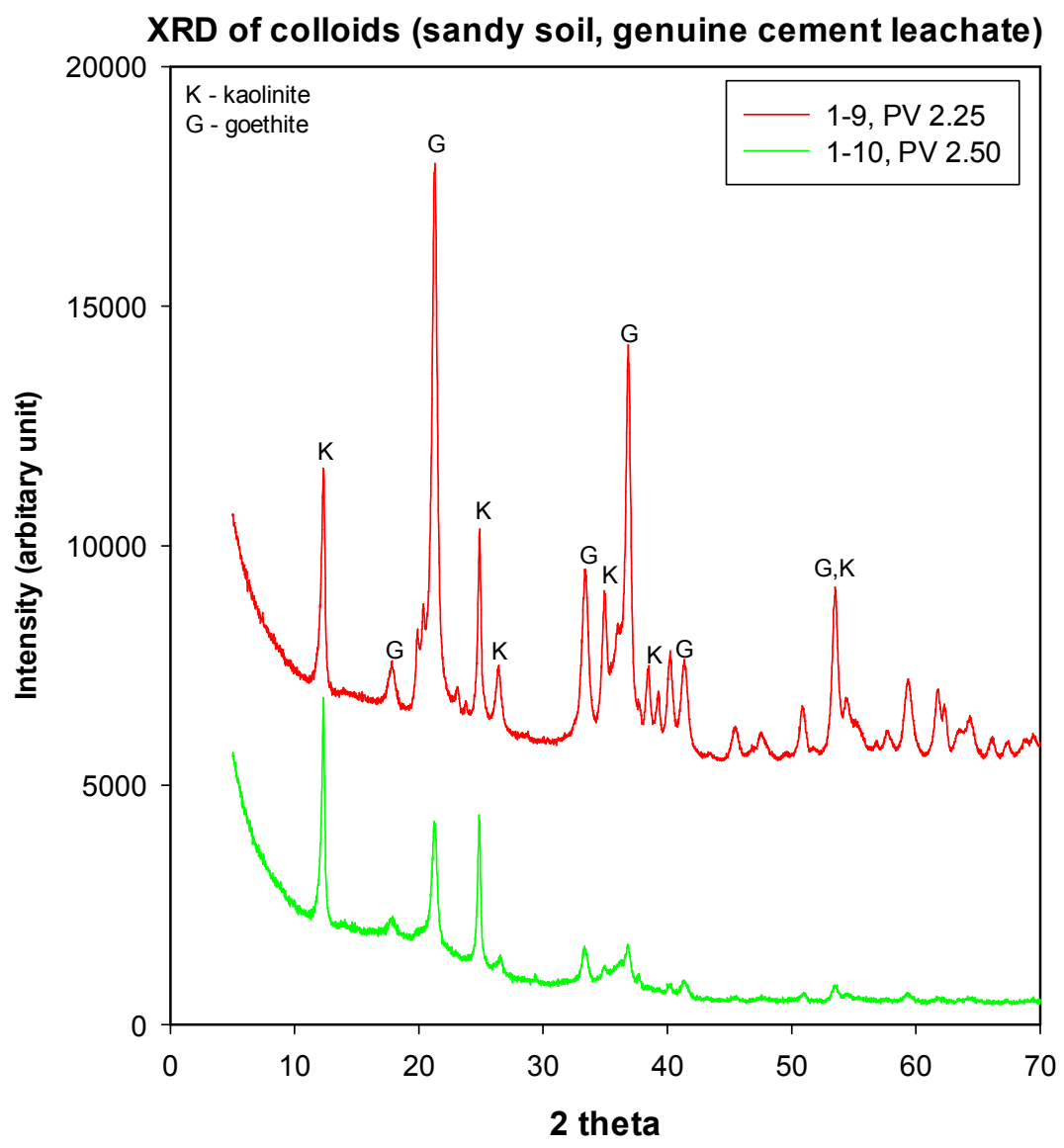

Figure 19. XRD patterns of mobile colloids from sandy sediment column by undiluted GCL.

\subsubsection{SEM and EDX}

The SEM images and EDX spectra of air-dried colloids collected in the SRS sandy sediment column by undiluted GCL are shown in Figure 20. The sample identification labels (1-9 and 1-10) are identical to those in Figure 17A. The SEM image of sample 1-9 indicated the presence of short rod-like and plate-like particles, the short rod-like particles are likely aggregates of nano-size goethite and the plate-like crystals are likely kaolinite. The average particles of the goethite are in the range of 250-350 nm, in good agreement with the mean particle size in PSD measurement. The goethite and kaolinite particles in the effluent samples were fairly stable and well dispersed; but after air-drying, the goethite particles tended to be aggregates and the smaller goethite particles tended to stick onto larger kaolinite particles. The EDX spectrum of sample 1-9 indicated the presence of the major elements $\mathrm{O}, \mathrm{Si}, \mathrm{Al}$ and $\mathrm{Fe}$, indicating that the major particles are $\mathrm{Fe}$ oxide or hydroxide like goethite $(\mathrm{FeOOH})$ and aluminum silicates like kaolinite $\left(\left(\mathrm{Al}_{2} \mathrm{Si}_{2} \mathrm{O}_{5}(\mathrm{OH})_{4}\right)\right.$, and maybe a small amount of hydroxyl-interlayered vermiculate 
(identified by the XRD computer as muscovite $\left.\left(\mathrm{KAl}_{2}\left(\mathrm{AlSi}_{3} \mathrm{O}_{10}\right)(\mathrm{F}, \mathrm{OH})_{2}\right)\right)$, qualitatively in good agreement its previous XRD identification. Based on the relative intensities of $\mathrm{Si}$, $\mathrm{Al}$ and $\mathrm{Fe}$, it appeared that kaolinite is about equal to or slightly more than goethite in abundance, slightly in contrast to the XRD intensity. Carbon is likely from the carbon tape in SEM sample preparation. In addition, small amount of $\mathrm{Ca}, \mathrm{P}, \mathrm{K}, \mathrm{Ti}, \mathrm{Mg}$ and $\mathrm{Cl}$ were detected, the corresponding mineral phases can not be firmly identified. It is simply speculated that $\mathrm{Na}$ may be from the solution precipitation, $\mathrm{K}$ may be related to muscovite $\left(\mathrm{KAl}_{2}\left(\mathrm{AlSi}_{3} \mathrm{O}_{10}\right)(\mathrm{F}, \mathrm{OH})_{2}\right)$, Ti may be in titanium oxide (e.g., like anatase as identified in XRD of $550{ }^{\circ} \mathrm{C}$ dried SRS sandy sediment), P may be from the surface coating of natural organic matters on the nano particles. The presence of $\mathrm{Ca}$ may indicate the formation of a tiny amount of calcite or $\mathrm{Ca}$ ion-exchanged or adsorbed onto colloids, which needs to be further studied.

In sample 1-10, it appeared that goethite particles tended to form larger sphere-like, rather than needle-like, aggregates. The EDX spectrum is qualitatively similar to that of sample 1-9: $\mathrm{Si}, \mathrm{Al}, \mathrm{Fe}$ and $\mathrm{O}$ are major element, indicating the presence of kaolinite and goethite, with a small amount of $\mathrm{K}, \mathrm{Ca}, \mathrm{P}$, and Ti. Again, the presence of $\mathrm{Ca}$ may indicate the formation of a tiny amount of calcite precipitate or $\mathrm{Ca}$ ion-exchanged or adsorbed onto colloids.
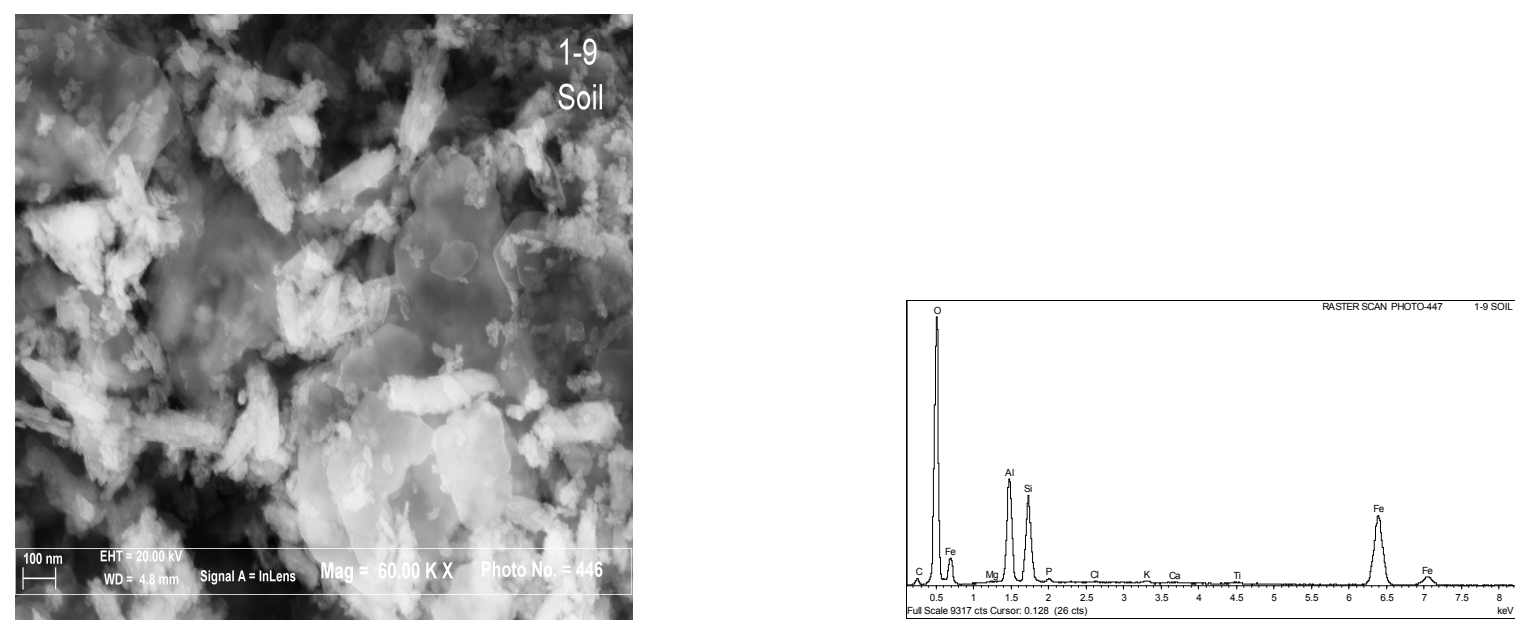

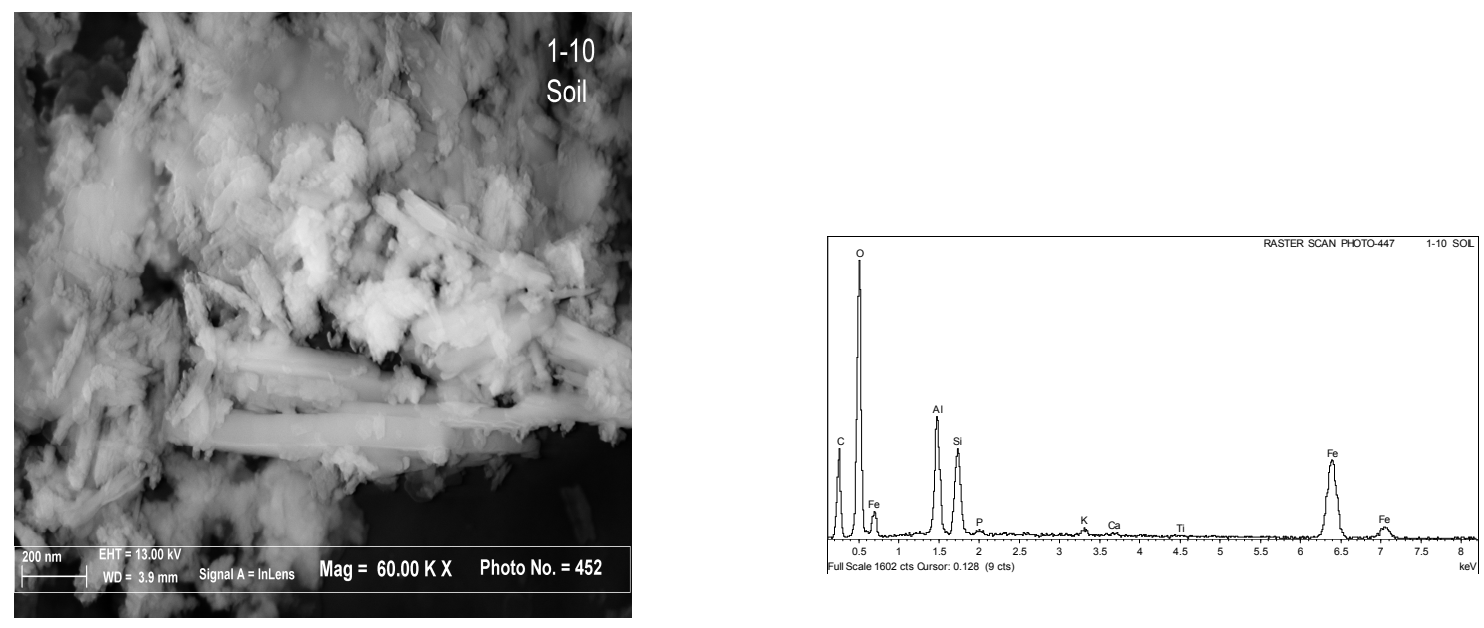

Figure 20. SEM and EDX of air-dried colloids from the SRS sandy sediment column by undiluted GCL. The sample identification labels, 1-9 and 1-10, are the same as shown in Figure 17A.

\subsubsection{PSD and Zeta potential}

For the effluent samples from column studies with 1:10 diluted GCL solutions at $\mathrm{pH}$ 11.74, the PSD and Zeta potential of colloids in the direct effluents were measured using ZetaPlus at SRNL. The sample preparation for these PSD and Zeta measurements were described as follows: (1) the effluents with mobilized colloids were kept in laboratory for $\sim 3$ months, the top clear liquid from each effluent was collected by pipetting and the remaining effluent with particles were shaken and re-dispersed; (2) a certain amount of colloids was transferred to the corresponding clear effluent solution to make the suspension of right colloid concentration for PSD and Zeta measurement. However, for effluent samples from undiluted GCL column study, the colloids in the effluents were diluted in GCL or DI water for PSD and Zeta potential measurements, because the top clear liquid had been used for ICP-OES measurement.

The results were given in Table 6, in which the measured mean particle size and Zeta potential of GCL, and the Zeta potentials of sandy sediment, kaolinite and goethite in GCL, were included. The measured mean size of GCL was zero, and Zeta potential of GCL jumped in a broad range, from -115.8 to $+28.1 \mathrm{mV}$, indicating that the concentration of particles in GCL was so low that the ZetaPlus was not able to collect a meaningful signal. Thus, the concentration of $\mathrm{Ca}(\mathrm{OH})_{2}$ in $\mathrm{GCL}$, if present, was too low to be detected, in good agreement with the solution chemistry of GCL in which the concentration of $\mathrm{Ca}(\mathrm{OH})_{2}$ was 0.0192 molal, below the solubility ( 0.185 gram $/ 100$ gram or 0.0245 molal) of $\mathrm{Ca}(\mathrm{OH})_{2}$ in pure water at $25^{\circ} \mathrm{C}$.

For undiluted GCL, the mobilized colloids in DI diluent was negatively charged, with the mean particle size from 241 (sample 1-9) to $745 \mathrm{~nm}$ (sample 1-10). The mobilized 
colloids in undiluted GCL diluent were positively charged with the mean particle size from 1037 (sample 10) to $1434 \mathrm{~nm}$ (sample 1-9), indicating the colloids might slightly agglomerated in the undiluted GCL diluent. The positive charge of colloids in undiluted GCL could not be due to the presence of $\mathrm{Ca}(\mathrm{OH})_{2}$ in the GCL because $\mathrm{Ca}(\mathrm{OH})_{2}$ precipitate was not expected and detected in this GCL; in addition, the $\mathrm{ZPC}$ of $\mathrm{Ca}(\mathrm{OH})_{2}$ is $\sim \mathrm{pH} 12.0$, even if $\mathrm{Ca}(\mathrm{OH})_{2}$ is present, its Zeta potential at $\mathrm{pH} 12.3$ should be near zero.

For 1:10 diluted GCL solution, the colloids in the direct effluents were all negatively charged. The mean particle sizes of the mobilized colloids in the direct effluents were in the range of 700-1550 $\mathrm{nm}$, which may indicated that the colloids might form slight agglomeration. However, by comparing with previous results from CLS study, it is likely that the colloids mobilized by GCL solutions have larger mean size than those mobilized by CLS solution. These results also confirmed that the colloids were mobilized only as both goethite and kaolinite have the same surface charge.

Table 6. Mean particle size and Zeta potential of colloids in the direct effluents of GCL column experiments

\begin{tabular}{|c|c|c|c|c|c|c|}
\hline Sample ID & $\begin{array}{l}\text { No. of } \\
\text { PV }\end{array}$ & $\begin{array}{l}\mathrm{pH} \text { of } \\
\text { effluent }\end{array}$ & $\begin{array}{l}\text { Conductivity } \\
\text { of effluent, } \\
\mathrm{mS} / \mathrm{cm}\end{array}$ & Diluent & $\begin{array}{l}\text { Mean size, } \\
\text { nm }\end{array}$ & $\begin{array}{l}\text { Zeta } \\
\text { potential, } \\
\mathrm{mV}\end{array}$ \\
\hline GCL & & 12.3 & 9.75 & GCL & 0.0 & $\begin{array}{l}-115.8 \text { to } \\
28.1\end{array}$ \\
\hline Sandy sediment & & & & GCL & & 14.97 \\
\hline Kaolinite & & & & GCL & & 6.37 \\
\hline Goethite & & & & GCL & & 24.50 \\
\hline \multicolumn{2}{|l|}{$\begin{array}{l}\text { Undiluted } \\
\text { GCL }^{(b)}\end{array}$} & 12.30 & \multicolumn{2}{|l|}{9.75} & & \\
\hline SS-CL-1-9 & 2.25 & 10.08 & 0.393 & GCL & $1434.2 \pm 23.1$ & $19.43 \pm 0.82$ \\
\hline SS-CL-1-9 (a) & 2.25 & & & DI & $241.5 \pm 1.3$ & $-23.28 \pm 0.55$ \\
\hline SS-CL-1-10 & 2.50 & 10.55 & 0.609 & GCL & $1037.6 \pm 21.7$ & $26.70 \pm 2.54$ \\
\hline SS-CL-1-10 (a) & 2.50 & & & DI & $754.1 \pm 6.1$ & $-25.25 \pm 0.60$ \\
\hline \multicolumn{2}{|l|}{$\begin{array}{l}\text { 1:10 diluted } \\
\text { GCL }^{(b)}\end{array}$} & 11.74 & \multicolumn{2}{|l|}{1.185} & & \\
\hline SS-CL-10-19 & 4.75 & 8.96 & 0.084 & Effluent & $1480.1 \pm 96.6$ & $-15.18 \pm 2.17$ \\
\hline SS-CL-10-20 & 5.00 & 9.22 & 0.072 & Effluent & $1177.0 \pm 29.0$ & $-18.61 \pm 0.65$ \\
\hline SS-CL-10-21 & 5.25 & 9.76 & 0.081 & Effluent & $1551.8 \pm 50.9$ & $-22.78 \pm 0.56$ \\
\hline SS-CL-10-22 & 5.50 & 9.41 & 0.086 & Effluent & $811.1 \pm 18.0$ & $-23.77 \pm 1.66$ \\
\hline SS-CL-10-23 & 5.75 & 9.62 & 0.127 & Effluent & $701.8 \pm 19.3$ & $-23.28 \pm 1.75$ \\
\hline SS-CL-10-24 & 6.00 & 9.71 & 0.123 & Effluent & $864.3 \pm 17.0$ & $-26.16 \pm 1.38$ \\
\hline
\end{tabular}

(a) The $\mathrm{pH}$ of the DI dilution was 7.51 for sample 1-9 and 8.35 for sample 1-10.

(b) $\mathrm{pH}$ and conductivity are those of influent leachate solutions. 


\section{Conclusions}

The objective of this study was to determine whether cementitious leachates would promote the in situ mobilization of natural colloidal particles from a SRS sandy sediment. The intent was to determine if a cementitious surface or subsurface structure would create plumes that could produce conditions conducive to sediment dispersion and mobile colloid generation, either by 1) mineral precipitation of the cement leachate interacting with SRS groundwater, or 2) the release of colloidal particles from a SRS sandy sediment. Several conclusions were drawn from this study.

(1) Titration experiments of SRS groundwater with CLS indicated that very little colloidal materials were generated through this pathway. What little that was precipitated, was too large to move through porous media. Meanwhile, the column study of SRS sandy sediment with AGW also demonstrated that colloidal particles only came out for a short duration, even when the dispersive cementitious water chemistry did not change, suggesting that not all the clay-size fraction will disperse into suspension.

(2) For both undiluted CLS and GCL, a sharp plume front formed, and mobile colloids were intensely mobilized within the colloid plume and then stopped releasing with further filtration of influents. The mobilized colloids were mainly goethite and kaolinite with the fraction ratios of goethite to kaolinite from $2: 1$ to $1: 1$.

(3) Released colloids were highly negatively charged and their mean particle sizes were primarily in a range of $200-470 \mathrm{~nm}$, and $<1000 \mathrm{~nm}$. It appeared that the colloids of smaller mean particle sizes were mobilized first, which is consistent with electrostatic and filtration theories (Ryan and Elimelech 1996; Bunn et al., 2002). Colloids of 100-470 $\mathrm{nm}$ are believed to be the most mobile colloids (Elimelech 1994; Zhuang et al., 2005); the mobilized colloids in porous media are normally not larger than $1 \mu \mathrm{m}$. The colloids of smaller sizes are preferentially mobilized and released because they have higher removal efficiencies.

(4) Although colloid mobilizations in subsurface zones are typically very complex and related to many factors, electrostatic forces of colloidal particles appeared to be the controlling mechanism in this case study. In normal subsurface environments, goethite has a positive surface charge, but quartz and kaolinite have negative surface charges, the nano-goethite and kaolinite are cemented together and stick to the sand surfaces due to electrostatic attraction. However, within the leachate plume, the SRS sand particles, kaolinite and goethite all have negative surface charges, and the nano-goethite and kaolinite are dispersed and mobilized due to their electrostatic repulsion.

(5) With dilution of the undiluted leachates, the plume fronts diminished with higher pore volumes showing broadening peaks and increasingly fewer colloids were mobilized, until no colloids were mobilized at the 1:1000 dilution. Mobilization or release of colloids is also related to their surface charge and thus the electrostatic behavior. While 
goethite has a negative surface charge in less diluted cement leachate solutions, all sandy particles, nano-goethite and kaolinite have negative surface charges and the colloids are released due to electrostatic repulsion. In contrast, in very diluted simulant solutions like 1:1000 diluted solution, its chemistries are fairly close to ordinary groundwater, goethite has a positive surface charge, but sand particles and kaolinite have negative surface charges, as a result, the goethite and kaolinite colloids are cemented together and not released due to the electrostatic attraction.

(6) With $\mathrm{pH}$ adjustment for the 1:10 diluted CLS solutions, the plume front diminished with higher pore volumes showing broadening peaks and increasingly fewer colloids were mobilized, until no colloids were released at $\mathrm{pH} \leq 9.87$. Whether colloids are mobilized or not also depend on the surface charge of goethite in the corresponding solutions.

(7) The colloids are intensively mobilized near the source of cement leachates. Progressively fewer colloids are released from the subsurface soils as the leachates transport in porous media, due to the influence of mixing with groundwater, infiltration of rainfall, and dissolution of soils minerals in the surrounding formations (e.g., to cause $\mathrm{pH}$ reduction).

(8) Together this data demonstrated that in situ homogeneous precipitation, which is simply the mixing of cement leachate with SRS groundwater (without a solid present), is not likely to result in the formation of a large amount of precipitated solid phases. Additionally, it was shown that a SRS subsurface system is not spontaneously dispersive, meaning that the subsurface clays tend to remain immobile due to natural electrostatic forces. However, when a cementitious leachate comes in contact ( $\mathrm{pH} 12.80$ to $\mathrm{pH} \sim 8$ ) with the sediment, colloid dispersion will occur as a sharp peak, containing a relatively high percentage of the clay-size particles in the sediment $(\sim 13 \%)$, after which, few colloids enter the mobile phase, although the aqueous chemical conditions of the system remain unchanged. Finally, within the cementitious plume we collected in situ precipitates, specifically a $\mathrm{Na}-\mathrm{CO}_{3}$ phase. Once the cement leachate became dilute by a factor of 1000 with a groundwater or if the $\mathrm{pH}$ dropped below $\sim 8$, depending on ion strength, then the tendency for colloids to be released was essentially undetectable.

\section{Reference}

Bates, J.K., Bradley, J.P., Teetsov, A., Bradley, C.R., and Brink, B.M., Colloid formation during waste form reaction-implications for nuclear waste disposal. Science, 1992, 256, 649-651.

Bradford, S.A., and Torkzaban, S., Colloid Transport and retention in unsaturated porous media: a review of interface-, collector-, and pore-scale processes and models. Vadose Zone J., 2008, 7, 667-681. 
Buesseler, K.O., Kaplan, D.I., Dai, M.H., and Pike, S., Source-dependent and sourceindependent controls on plutonium oxidation state and colloid associations in groundwater. Environ. Sci. Tech., 2009, 43, 1322-1328.

Bunn, R.A., Magelky, R.D., Ryan, J.N., and Elimelech, M., Mobilization of natural colloids from an iron oxide-coated sand aquifer: effect of $\mathrm{pH}$ and ionic strength. Environ. Sci. Tech., 2002, 36, 314-322.

Chen, Q.Y., Tyrer, M., Hills, C.D., Yang, X.M., and Carey, P., Immobilization of heavy metal in cement-based solidification/stabilization: A review. Waste Management, 2009, $29,390-403$.

Contardi, J.S., Turner, D.R., and Ahn, T.M., Modeling colloid transport for performance assessment. J. Contam. Hydro., 2001, 47, 323-333.

Crist, J.T., Zevi, Y., McCarthy, J.F., Throop, J.A., and Steenhuis, T.S., Transport and retention mechanisms of colloids in partially saturated porous media. Vadose Zone J., 2005, 4, 184-195.

Cristiano, E., Hu, Y.J., Siegfried, M., Kaplan, D.I., and Nitsche, H., A comparison of point of zero charge measurement methodology. Clay \& Clay Minerals. 2011, 59, 107115.

Dai, M.H., Kelley, J.M. and Buesseler, K.O., Sources and migration of plutonium in groundwater at the Savannah River Site. Environ. Sci. Tech., 2002, 36, 3690-3699.

Dai, M.H., Buesseler, K.O., and Pike, S.M., Plutonium in groundwater at the 100K-area of the U.S. DOE Hanford Site. J. Contam. Hydro., 2005, 76, 167-189.

DeNovio, N.M., Saier, J.E., and Ryan, J.N., Colloid movement in unsaturated porous media: recent advances and future directions. Vadose Zone J., 2004, 3, 338-351.

Elimelech, M., and O'Melia, C.R., Effect of particle-size on collision efficiency in the deposition of Brownian particles with electrostatic energy barrier. Langmuir, 1990, 6, 1153-1163.

Elimelech, M., Effect of particle size on the kinetics of particle deposition under attractive double layer interaction. J. Colloid Interface Sci., 1994, 164, 190-199.

Environmental Protection Agency, Method 6010C - Inductively coupled plasma-atomic emission spectrometry, Rev 03, 2007.

Flury, M., Mathison, J.B., and Harsh, J.B., In situ mobilization of colloids and transport of cesium in Hanford sediment. Environ. Sci. Tech., 2002, 36, 5335-5341. 
Goldberg, S., Criscenti, L.J., Turner, D.R., Davis, J.A, and Cantrel, K.J., Adsorptiondesorption processes in subsurface reactive transport modeling. Vadose Zone, J., 2007, 4, 407-435.

Grolimund, D., and Borkovec, M., Release of colloidal particles in natural porous media by monovalent and divalent cations. J. Contam. Hydro., 2006, 87, 155-175.

Grolimund, D., and Borkovec, M., Colloid-facilitated transport of strongly sorbing contaminants in natural porous media: mathematical modeling and laboratory column experiments. Environ. Sci. Tech., 2005, 39, 6378-6386.

Grolimund, D., Elimelech, M., Borkovec, M., Barmettler, K., Kretzschmar, R., and Sticher, H., Transport of in situ mobilized colloidal particles in packed soil columns. Environ. Sci. Tech., 1998, 32, 3562-3569.

Grolimund, D., Barmettler, K., and Borkovec, M., Release and transport of colloidal particles in natural porous media: 2. Experimental results and effects of ligands. Water Resour. Res., 2001, 37 (3), 571-582

Huber, N., Baumann, T., and Niessner, R., Assessment of colloid filtration in natural porous media with spatially variable aperture. Environ. Sci. Tech., 2000, 34, 3774-3779.

Kaplan, D.I., Subsurface mobile colloids: their surface characterization, mineralogy, and roles in contamiant transport in a coastal plain aquifer. Ph.D. Dissertation. University of Georgia, 1993.

Kaplan, D.I., Bertsch, P.M., Adriano, D.C., and Miller W.P., Soil-borne mobile colloids as influenced by water flow and organic carbon. Environ. Sci. Tech., 1993, 27, 11931200.

Kaplan, D.I., Bertsch, P.M., and Adriano, D.C., Facilitated transport of contaminant metals through an acidified aquifer. Ground Water, 1995, 33, 708-717.

Kaplan, D.I., Bertsch, P.M., Adriano, D.C., and Orlandini, K.A.. Actinide association with groundwater colloids in a coastal plain aquifer. Radiochim. Acta, 1994a, 66-67, 181-187.

Kaplan, D.I., Sumner, M.E., Bertsch, P.M., and Adriano, D.C., Chemical conditions conducive to the release of mobile colloids from ultisol profiles. Soil Sci. Soc. Am. J., 1996, 60, 269-274.

Kaplan, D.I., Hunter, D.B., Bertsch, P.M., Bajt, S., and Adriano, D.C., Application of synchrotron X-ray fluorescence spectroscopy and energy dispersive X-ray analysis to identify contaminant metals on groundwater colloids. Environ. Sci. Tech., 1994b, $28,1186-1189$. 
Kaplan D.I., Geochemical data package for performance assessment calculations related to the Savannah River Site. SRNL-STI-2009-00473, Aiken, SC 29808, 2010.

Kersting, A.B., Efurd, D.W., Finnegan, D.L., Rokop, D.J., Smith, D.K., and Thompson, J.L. Migration of plutonium in groundwater at the Nevada Test Site. Nature, 1999, 397, 56-59.

Kretzschmar, R., Borkovec, M., Grolimund, D., and Elimelech, M., Mobile subsurface colloids and their role in contaminant transport. Adv. Agron., 1999, 66, 121-193.

Kretzschmar, R., and Schafer, T., Metal retention and transport on colloidal particles in the environment. Elements, 2005, 1, 205-210.

Li, J.F., and Wang, J.L., Advances in cement solidification technology for waste radioactive ion exchange resins: a review. J. Hazard. Mat., 2006, B135, 443-448.

Mayer, L.M., and L.L. Schick, Removal of hexavalent chromium from estuarine waters by model substrates and natural sediments. Environ. Sci. Tech., 1981, 15 (12), 14821484.

McCarthy, J.F., and Degueldre, C., Sampling and characterization of colloids and particles in ground water for studying their role in contaminant transport. In: van Leeuwen, H.P., Buffle, J. (Eds.), Environmental Particles. Environmental Analytical and Physical Chemistry Series. Lewis Publisher, Chelsea, MI., 1993.

McCarthy, J.F., and McKay, L.D., Colloid transport in the subsurface: past, present, and future challenges. Vadose Zone J., 2004, 3, 326-337.

McCarthy, J.F., and Zachara, J.M., Subsurface transport of contaminants. Environ. Sci. Tech. 1989, 23, 496-502.

Miller, W.P., and Miller, D.M., A micro-pipette method for soil mechanical analysis. Commum. Soil Sci. Plant Anal., 1987, 18, 1-15.

Milestone, N.B., Reaction in cement encapsulated nuclear wastes: need for toolbox of different cement types. Adv. Applied Ceramics, 2006, 105, 13-20.

Moridis, G.J., Hu, Q., Wu, Y.S., and Bodvarsson, G.S., Preliminary 3-D site-scale studies of radioactive colloid transport in the unsaturated zone at Yucca Mountain, Neveda. J. Contamin. Hydro., 2003, 60, 251-286.

Newman, M.E., Effects of alterations in groundwater chemistry on the mobilization and transport of colloids. Ph.D. Dissertation, Clemson University, 1990.

Ouyang, Y., Shinde, D., Mansell, R.S. and Harris, W., Colloid-enhanced transport of chemicals in subsurface environments: A review. Critical Reviews in Environ. Sci. Tech., 1996, 26, 189-204. 
Petosa, A.R., Jaisi, D.P., Quevedo, I.R., Elimelech, M., and Tufenkji, N., Aggregation and deposition of engineered nanomaterials in aquatic environments: role of physicochemical interactions. Environ. Sci. Tech., 2010, 44, 6532-6549.

Ptáček, P., Kubátová, D., Havlica, J., Brandštetr, J., Šoukal, F., and Opravil, T., Isothermal kinetic analysis of the thermal decomposition of kaolinite: The thermogravimetric study. Thermochimica Acta, 2010, 501, 24-29.

Roy, S.B., and Dzombak, D.A., Colloid release and transport processes in natural and model media. Colloids Surf., A, 1996, 107, 245-262.

Roy, S.B., and Dzombak, D.A., Chemical factors influencing colloid-facilitated transport of contaminants in porous media. Environ. Sci. Tech., 1997, 31, 656-664.

Ryan, J.N., and Elimelech, M., Colloid mobilization and transport in groundwater. Colloids Surf., A, 1996, 107, 1-56.

Ryan, J.N., and Gschwend, P.M., Colloid mobilization in two Atlantic coastal plain aquifers: field studies. Water Resource Res., 1990, 26, 307-322.

Ryan, J.N., and Gschwend, P.M., Effects of ionic strength and flow rate on colloid release: relating kinetics to intersurface potential energy. J. Colloid Interface Sci., 1994a, $164,21-34$.

Ryan, J.N., and Gschwend, P.M., Effects of solution chemistry on clay colloid release from an iron oxide-coated aquifer sand. Environ. Sci. Tech., 1994b, 28, 1717-1726.

Ruan, H.D., Frost, R.L., and Kloprogge, J.T., The behavior of hydroxyl units of synthetic goethite and its dehydroxylated product hematite. Spectrochimica Acta Part A: Molecular and Biomolecular Spectroscopy, 2001, 57, 2575-2586.

Seaman, J.C., Bertsch, P.M., and Miller, W.P., Physicochemical and mineralogical controls on colloids migration and deposition within sediment on the SRS. WSRC-RP94-276, Aiken, SC 29808, 1994.

Seaman, J.C., Bertsch, P.M., and Miller, W.P., Chemical controls on colloid generation and transport in a sandy aquifer. Environ. Sci. Tech., 1995, 29, 1808-1814.

Seaman, J.C., Bertsch, P.M., and Strom, R.N., Characterization of colloids mobilized from Southeastern coastal plain sediment. Environ. Sci. Tech., 1997, 31, 2782-2790.

Seaman, J.C., Bertsch, P.M., and Kaplan, D.I., Spatial and temporal variability in colloid dispersion as a function of groundwater injection rate within Atlantic coastal plain sediments. Vadose Zone J. 2007, 6, 363-372. 
Seaman, J.C., and Bertsch, P.M., Selective colloid mobilization through surface-charge manipulation. Environ. Sci. Tech., 2000, 34, 3749-3755.

Sen, T.K., and Khilar, K.C., Review on subsurface colloids and colloid-associated contaminant transport in saturated porous media. Advances in Colloid and Interface Science, 2006, 119, 71-96.

Sen, T.K., Processes in pathogenic biocolloidal contaminants transport in saturated and unsaturated porous media: a review. Water Air Soil Pollut., 2011, 216, 239-256.

Serkiz, S.M., Iverson, G.M., and Kaplan, D.I., Phase I - laboratory study: effects of cement grout structures on colloid formation from SRS soil. WSRC-TR-2000-0342, Aiken, SC 29808, 2000.

Serne, R.J., Criscenti, L.J., and Strachan, D.M. Comparison of geochemical code predictions and laboratory test results for uranium leaching/adsorption from cement. PNL-11508, Pacific Northwest National Laboratories, Richland, WA, 1987.

Strom, R.N., and Kaback, D.S., SRP Baseline Hydrogeologic Investigation: Aquifer Characterization Groundwater Geochemistry of the Savannah River Site and Vicinity (U) WSRC-RP-92-450. Westinghouse Savannah River Company, Environmental Sciences Section, Aiken, SC, 1992.

Tufenkji, N., and Elimelech, M., Correlation equation for predicting single-collector efficiency in physiochemical filtration in saturated porous media. Environ. Sci. Tech., 2004, 38, 529-536.

Wan, J.M., Tokunaga, T., Saiz, E., Larsen, J.T., Zheng, Z.P., and Couture, R.A., Colloid formation at waste plume fronts. Environ. Sci. Tech. 2004, 38, 6066-6073.

Wan, J.M., and J.L. Wilson., Visualization of the role of the gas-water interface on the fate and transport of colloids in porous media. Water Resource Res., 1994a, 30, 11-23.

Wan, J.M., and J.L. Wilson., Colloid transport in unsaturated porous media. Water Resource Res., 1994b, 30, 857-864.

Zachara, J.M., Serne, J., Freshley, M., Mann, F., Anderson, F., Wood M., Jones, T., and Myers, D., Geochemical processes controlling migration of tank wastes in Hanford's vadose zone. Vadose Zone J., 2007, 6, 985-1003.

Zhuang, J., Flury, M., and Jin, Y., Colloid-facilitated Cs transport through watersaturated Hanford sediment and Ottawa sand. Environ. Sci. Tech., 2003, 37, 4905-4911.

Zhuang, J., Jin, Y., and Flury, M., Comparison of Hanford colloids and kaolinite transport in porous media. Vadose Zone J., 2004, 3, 395-402. 
Zhuang, J., Qi, J., and Jin, Y., Retention and transport of amphiphilic colloids under unsaturated flow conditions: effect of particle size and surface property. Environ. Sci. Tech., 2005, 39, 7853-7859. 
Distribution:

S. L. Marra, 773-A - Rm. A-230

H. H. Burns, 773-41A - Rm.214

B. T. Butcher, 773-43A - Rm.212

L. B. Collard, 773-43A - Rm.207

D. A. Crowley, 773-43A - Rm.216

G. P. Flach, 773-42A - Rm. 211

R. A. Hiergesell, 773-43A - Rm.218

D. I. Kaplan, 773-43A - Rm.215

K. A. Roberts, 773-43A - Rm.225

F. G. Smith, III 773-42A - Rm.178

G. A. Taylor, 773-43A - Rm.230

R. S. Aylward, 773-42A - Rm. 281

J. J. Mayer II, 773-42A - Rm. 242

John C. Seaman: Savannah River Ecology Laboratory, University of Georgia, Aiken, SC 29808

(1 file copy \& 1 electronic copy), Building 999W - Room 326 